\title{
Palmitoleik Asidin Moleküler Yapısı, Titreșim Spektrumları ve Elektronik Özelliklerinin Teorik Olarak Íncelenmesi
}

\author{
Tuğba Göcen ${ }^{1 *}$, M. Haluk Güven ${ }^{2}$
}

öZ

Kabul / Accepted: 20/10/2020

\begin{abstract}
$\mathrm{Bu}$ çalışmada, Palmitoleik Asit (cis-9-Hekzadekanoik asit, C16:1, POA) 'in moleküler yapısı, titreşimsel spektroskopik ve elektronik özellikleri Gaussian 09 paket programı kullanılarak DFT/B3LYP/6-311++G(d,p) seviyesinde incelenmiştir. $\mathrm{POA}^{\prime}$ nın kristal yapısının henüz belirlenmediğinden, optimize edilmiş geometrik parametreleri (bağ uzunluğu, bağ açıları ve dihedral açılar), POA' ya izomorf olan Oleik asidin (OA) deneysel geometrik parametreleriyle karşılaştırılmışıır. POA' nın harmonik titreşim frekansları hesaplanmış ve literatürden elde edilen deneysel titreşim frekansları ile karşılaştırılmıştır. Titreşim frekanslarının işaretlemeleri, VEDA 4 programı kullanılarak potansiyel enerji dağılımı (PED) analizi ile gerçekleştirilmiştir. POA'nın hesaplanan yapısal parametreleri ve titreşim frekansları deneysel verilerle uyumludur. Molekülün elektronik özellikleri, en yüksek dolu moleküler orbital (HOMO) ve en düşük boş moleküler orbital (LUMO) temeline dayanılarak belirlenmiştir. HOMO-LUMO enerjileri arasındaki yüksek enerji aralığı molekülün kimyasal kararlılı̆ga ve düşük reaktiviteye sahip olduğunu gösterir. Moleküler elektrostatik potansiyel (MEP) yüzey haritası, mulliken atomik yükleri ve sertlik, yumuşaklık, elektronegatiflik, kimyasal potansiyel, iyonizasyon potansiyeli, elektron afinitesi, elektrofilik indeks, dipol moment gibi kuantum kimyasal tanımlayıcıları moleküldeki etkileşim bölgelerini belirlemek için hesaplanmıştır. Ayrıca, POA' nın 1sı kapasitesi, entropi ve entalpi gibi termodinamik özellikleri farklı sıcaklıklarda hesaplanmıştır. Tüm termodinamik parametreler, artan sicaklıkla birlikte artmıştır.
\end{abstract}

\footnotetext{
1*Sorumlu yazar iletişim: tugba_gocen@beun.edu.tr (https://orcid.org/0000-0003-0078-8531)

Ahmet Erdogan Vocational School of Health Services, Zonguldak Bülent Ecevit University, Zonguldak, Turkey

2İletişim: halukguven@yahoo.com (https://orcid.org/0006-0003-0475-3088)

Department of Physics, Zonguldak Bülent Ecevit University, Zonguldak, Turkey
} 


\title{
The Theoretical Investigation of Molecular Structure, Vibrational Spectra and Electronic Properties of Palmitoleic Acid
}

\begin{abstract}
In this study, the molecular structure, vibrational spectroscopic and electronic properties of Palmitoleic Acid (cis-9-Hexadecenoic acid, C16:1, POA) were investigated using the Gaussian 09 package program at DFT/B3LYP/6-311++G(d,p) level. Since the crystal structure of POA has not been determined yet, the optimized geometric parameters (bond length, bond angles and dihedral angles) were compared with experimental geometric parameters of Oleic acid (OA) which is isomorphous to the POA. The harmonic vibrational frequencies of the POA were calculated and compared with the experimental vibrational frequencies which obtained from the literature. The assignments of the vibrational frequencies were performed by potential energy distribution (PED) analysis by using VEDA 4 program. The calculated structural parameters and vibrational frequencies of POA are in good agreement with the experimental data. The electronic properties of the molecule were defined on the basis of the highest occupied molecular orbital (HOMO) and the lowest unoccupied molecular orbital (LUMO). The high energy gap between HOMO-LUMO energies shows that the molecule has chemical stability and low reactivity. Molecular electrostatic potential (MEP) surface map, mulliken atomic charges and quantum chemical descriptors such as hardness, softness, electronegativity, chemical potential, ionization potential, electron affinity, electrophilic index, dipole moment were calculated to determine interaction sides in the molecule. Besides, the thermodynamic properties such as heat capacity, entropy, and enthalpy of POA at different temperatures were calculated in gas phase. All thermodynamic parameters increased with increasing temperature.
\end{abstract}

Keywords- Palmitoleic Acid, Density Functional Theory (DFT), Vibrational Analysis, HOMO, LUMO 


\section{GİRIŞ}

Doymamış yağ asitleri, biyolojik organizmaların fonksiyonel aktivitelerinde kritik rol oynayan çok önemli lipit molekülleridir[1]. Doymamış yağların ve lipitlerin fiziksel ve kimyasal özelliklerini etkileyen ana faktörler, çift bağların sayısı, pozisyonu ve konfigürasyonudur [2]. Doymamış yağ asitlerindeki çift bağlar, alkil gruplarının nispi pozisyonlarına bağlı olarak, cis veya trans konfigürasyonunda bulunabilir ve bu konfigürasyonlar biyolojik süreçlerde önemli rol oynar. Trans konfigürasyonundaki (trans yağlar) doymamış yağ asidi doğada bulunmaz ancak margarin, atıştırmalık yiyecek, kekler ve kızartma fast foodlarında kullanılmak üzere endüstriyel olarak (hidrojene yağlar) üretilir. Trans yağların obezite, safra taşı hastalı̆̆ı ve koroner kalp hastalı̆̆ gibi sağlık problemleri oluşturduğu bildirilmiştir[3].

Palmitoleik asit (cis-9-Hexadecenoic acid, $\mathrm{C} 16: 1, \mathrm{POA}$ ), hidrokarbon zincirinin bir ucunda $\mathrm{CH}_{3}$ metil grubu, bu gruptan sonra 9. ve 10. karbon atomları arasında çift bağına (doymamışlık yeri) sahip olan, hidrokarbon zincirinin diğer ucunda ise aktifliğini veren karboksilik asit (- $\mathrm{COOH})$ grubu bulunan en yaygın omega-7 yağ asitlerinden biridir. POA yabani iğde ve macadamia findığından elde edilen bitkisel yağlarda bulunan yağ asididir. POA, insan diyetinde ve kan plazmasındakitekli doymamış yağ asidi bileşenidir, tüm dokularda bulunur ancak genellikle karaciğerde daha yüksek konsantrasyonlarda bulunur. Bu yağ asidi seçici bir bakterisit etkiye sahiptir; S. aureus, Streptococcus salivarius, Fusobacterium nucleatum, Neisseria gonorrhoea ve Helikobakter pilori gibi bazı zararlı bakterilere karşı antibakteriyel aktiviteler ve bakterisidal özellikler sergilerken, faydalı bakterileri öldürmez[4]. Yapılan son çalışmalar, POA'nın cilt hiperpigmentasyonu [5], fibroz $[6,7]$ ile ilişkili bozuklukların tedavisinde ve gram-pozitif bakterilerin neden olduğu ikincil enfeksiyonların tedavisinde kullanılan formülasyonlarda ek fayda sağladığınıgöstermektedir.

PAO takviyesinin ateroskleroz gibi karmaşı metabolik ve enflamatuar hastalıklara karşı önleyici özellikler sergilediği bildirilmiştir. Cis-PAO' nun ateroskleroz üzerindeki etkisinin, anti-enflamatuar etkileri ve özellikle inflamazom aktivasyonunu önleme yoluyla gerçekleştirdiği görülmektedir.Farelerde cis-PAO takviyesinin, bu biyoaktif lipitin hiperlipidemiye bağlı ER (endoplazmik retikulum) stresini, inflamazom aktivasyonunu ve enflamasyonu önlediğini ve böylece aterosklerozun ilerlemesini azalttığını göstermiştir. PAO'nun cis izomeri, hücre içi organel membranların yeniden düzenlenmesi yoluyla ateroskleroza karşı koruyucu bir etki gösterdiği bildirilmiştir.Ayrıca, cis-PAO takviyesinin kalp-damar hastalıklarını önleyebileceği yapılan çalışmalar sonucu gösterilmiştir [8]. Yapılan çalışmalar cis-POA'nın aksine trans-PAO takviyesinin, lipit kaynaklı ER stresi, inflamazom aktivasyonunu ve aterosklerozu önleyemediği veya arttırmadığını göstermiştir [9].

POA'nın molekül yapısı ve spektroskopik özellikleri üzerine yapılan deneysel çalışmalar; POA'nın $\alpha$ (SCT konformasyon) ve $\gamma$ (SCS' konformasyon) olarak adllandırılan iki fazda kristallendiğini göstermiştir [10]. Aynı çalışmada, FT-Raman spektroskopisi ile POA' nınfaz geçişi incelemiştir. Yapılan çalışmalar, POA'nın $\gamma$ fazının kristal yapısı henüz tam olarak belirlenmemiş olmasına rağmen, bu formun Oleik asidin (cis-9Octadecenoic acid) $\gamma$ fazına izomorf olduğunu göstermektedir. Ayrıca, POA' nın $\gamma$ formunun, Oleik asidin $\gamma$ formu ile aynı spektral özellikleri sergilediği yapılan deneysel çalışmalarla desteklenmiştir [11].

Bir molekülün biyolojik özelliklerinin ve aktivitesinin moleküler yapıya bağlı olması sebebiyle, yapısal ve fonksiyonel özelliklerinin belirlenmesi büyük önem taşımaktadır. Teorik hesaplama metodları ile ilgili çalışma alanları moleküller özelliklerin belirlenmesinde önemli rol oynamaktadır. Moleküler, spektroskopik ve elektronik yapının kuantum kimyasal yöntemlerle öngürülmesi ise, deneysel verilerle tutarlı kesin sonuçlar vermesi nedeniyle değerli hale gelmiştir.

Pek çok biyolojik süreçte önemli rol oynaması ve kalp-damar hastalıklarında önleyici-koruyucu etkilere sahip oluşu POA' ya günümüzde hızla büyüyen bir popülarite kazandırmıştır. Ancak şimdiye kadar yapılan çalışmalarda POA' nın yapı-fonksiyon ilişkilerinin saptandı̆̆ı teorik hesaplamalara rastlanmamıştır.Bu sebeple POA üzerinde standart hesaplama yöntemi olan DFT yardımıyla kapsaml1-sistematik bir geometrik optimizasyon ve titreşimsel analiz gerçekleştirilmiştir. Ayrıca, MEP haritalarının yorumlanması ve Mulliken yüklerinin belirlenmesi molekülün kimyasal bağlanmadaki aktif bölgelerin tayininde anahtar rol oynamaktadır. POA'nın MEP yüzeyi, yapı-aktivite ilişkisinin tahmini için haritalanmıştır. Bunun yanı sıra, POA'nın sınır moleküler orbitalleri (HOMO ve LUMO), kuantum kimyasal tanımlayıcıları ve farklı sicaklıklarda termodinamik özellikleri hesaplanmıştır. Yaptığımız bu teorik çalışma, mevcut molekülün geometrik yapısını, titreşimsel 


\begin{tabular}{|c|c|c|}
\hline & $\begin{array}{l}\text { BŞEÜ Fen Bilimleri Dergisi } \\
7(2), 553-573,2020\end{array}$ & $\begin{array}{r}\text { BSEU Journal of Science } \\
\text { DOI: } 10.35193 / \text { bseufbd. } 741065\end{array}$ \\
\hline & & 58-7575 (http://dergipark.gov.tr/bseufbd) \\
\hline
\end{tabular}

analizini ve elektronik özelliklerini eksiksiz bir şekilde tanımlamayı ve bu sayede ilaç-reseptör etkileşimini anlamayı amaçlamaktadır.

\section{HESAPLAMA YÖNTEMLERİ}

Bu çalışmada tüm kuantum kimyasal hesaplamalar, DFT (B3LYP) yöntemi 6-311++G(d,p) baz seti ve Gaussian09[12] programı kullanılarak gerçekleştirilmiş̧ir. Standart geometrik parametrelerden yola çıkılarak POA' nın $\gamma$ formunungiriş geometrisi oluşturulmuş ve DFT/B3LYP/6-311++G(d,p) teori düzeyinde optimize edilmiştir. Optimize geometrik yapıdan yola çıkılarak aynı yöntemle harmonik titreşim frekansları hesaplanmıştır. POA'nın optimize edilmiş geometrisinde sanal titreşim frekansına sahip bir titreşim modu bulunmadığından, elde edilen yapının potansiyel enerji yüzeyinde gerçek bir minimuma karşllık geldiğini söyleyebiliriz. DFT/B3LYP/6-311++G(d,p) teori düzeyinde harmonik yaklaşıklıkla hesaplanan dalgasayıları ile deneysel dalgasayıları arasındaki uyumu sağlamak amacıyla, hesaplanan dalgasayıları, titreşim dalgasayılarının $1700 \mathrm{~cm}^{-1}$ 'e eşit veya daha büyük değerleri için 0,958 ile ve $1700 \mathrm{~cm}^{-1}$ 'in altındaki değerleri için 0,983 ile çarpılarak ölçeklendirilmiştir[13].Spektral işaretlemeler için ayrıntılı olarak PED (Potansiyel Enerji Dağılımı) hesabı, VEDA 4 programında[14]yapılmış ayrıca GaussView 5.0.8 [15]arayüzde bulunan spektrum animasyon programından da yararlanılmıştır.

Analiz edilen molekülün reaktivitesini ve molekül içindeki yük transferine ilişkin bilgileri açıklamak için molekülün Mulliken atomik yükleri, sınır moleküler orbital (HOMO-LUMO) enerjileri, moleküler elektrostatik potansiyel (MEP) yüzeyi, kuantum kimyasal tanımlayıcıları (kimyasal sertlik, yumuşaklık, elektronegatiflik, kimyasal potansiyel, elektrofilik indeks, iyonizasyon potansiyeli, elektron afinitesi, dipol moment gibi) aynı teori düzeyinde hesaplanmıştır. Ayrıca, POA'nın termodinamik fonksiyonlarındaki değişiklikler (1sı kapasitesi, entropi ve entalpi), titreşim frekansı hesaplamalarından yola çıkılarak farklı sıcaklıklar için araştırılmıştır.

\section{BULGULAR}

\section{A. Moleküler Geometri}

Standart geometrik parametrelerden üretilen POA' nın ilk geometrisi GaussView 5.0.8 moleküler görüntüleme programındaçizilmiş ve potansiyel enerji yüzeyinde herhangi bir kısıtlama olmaksızın minimize edilmiştir.Optimizasyon için, kutuplanma etkisini gidermek, uyarılmış ve iyonik moleküllerde elektron yoğunluğunun dağınıklığını modellemek için eklenen difuse ve polarize fonksiyonlarını içeren $6-311++\mathrm{G}(\mathrm{d}, \mathrm{p})$ baz seti kullanılmıştır. Molekülün yapısı, $C_{1}$ nokta grubu simetrisine sahiptir ve toplam enerjisi 778,0377435200 au olarak hesaplanmıştır. POA' nın optimize edilmiş geometrik parametreleri (bağ uzunluğu, bağ açıları, dihedral açılar) kristal yapısı henüzbelirlenemediği için, izomorfu olan ve spektral özellikleri benzerlik gösteren Oleik asidin (cis-9-Octadecenoic acid, C18:1, OA) $\gamma$ formununCambridge yap1 veri bankasından alınan (REF CSD kod: OLECAC,1226004) tek kristal X-1̧̧ını kırınımı (XRD) verileriyle karşılaştırılmış ve sonuçlar Tablo l' de sunulmuştur. POA' nın optimizasyon sonucu elde edilen geometrik yapısı ve izomofu olan OA'nın kristal yapısı Şekil 1' de atomik numaralarıyla gösterilmiştir. 


\begin{tabular}{|c|c|c|}
\hline & $\begin{array}{l}\text { BŞEÜ Fen Bilimleri Dergisi } \\
7(2), 553-573,2020\end{array}$ & $\begin{array}{r}\text { BSEU Journal of Science } \\
\text { DOI: } 10.35193 / \text { bseufbd.741065 }\end{array}$ \\
\hline ERSI & & 58-7575 (http://dergipark.gov.tr/bseufbd) \\
\hline
\end{tabular}

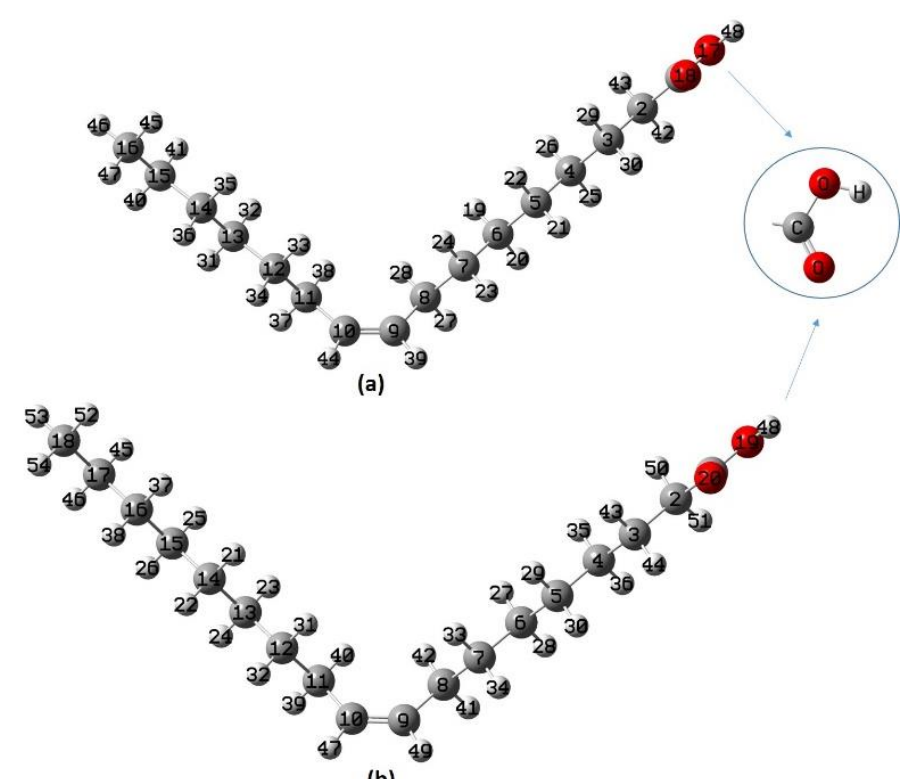

(b)

Şekil 1. (a) POA'nın B3LYP/6-311++G(d,p) seviyesinde optimize edilmiş geometrik yapısı(b) POA'nın izomorfu olan OA' nın kristal yapısı ve karboksil $(-\mathrm{COOH})$ gruplarıyla gösterimi

POA' nın molekül yapısı incelendiğinde, bir $\mathrm{C}=\mathrm{C}$ bağı ile ayrılan iki bölümden oluştuğu kabul edilebilir. Molekülün bir tarafında, metil taraflı zincir olarak adlandırılan bir metil grubu bulunurken, diğer tarafında terminal grubu (karboksil taraflı zincir) olarak karboksil grubu bulunur. POA' nın $\gamma$ formunun $\mathrm{C}(8)$ $\mathrm{C}(9)=\mathrm{C}(10)-\mathrm{C}(11)$ olefin grubuna ait dihedral açıları sırasılya skew $\left(\mathrm{S}=120^{\circ}\right)$, cis $\left(\mathrm{C}=0^{\circ}\right)$ ve skew' $\left(\mathrm{S}^{\prime}=-120^{\circ}\right)$ olarak tanımlanmış ve $\mathrm{C}-\mathrm{C}=\mathrm{C}-\mathrm{C}$ grubunun konformasyonun SCS' olduğu bildirilmiştir [10].POA' nın optimize edilmiş yapısında, olefin gruba ait $C(7)-C(8)-C(9)=C(10), C(8)-C(9)=C(10)-C(11)$ ve $C(9)=C(10)-C(11)-C(12)$ dihedral açıları sırasıyla $119.3^{\circ},-0.2^{\circ}$ ve $-122.6^{\circ}$ olarak hesaplanmıştır. Böylece, $-\mathrm{C}-\mathrm{C}=\mathrm{C}-\mathrm{C}-$ grubunun konformasyonu, yukarıdaki dihedral açı notasyonuna uygun olarak, $\mathrm{SCS}^{\prime}$ bulunmuştur ve $\gamma$ formunun kristal yapısında önerilen yapıyla aynı konformasyona sahiptir.

$\mathrm{C} 1=\mathrm{O} 18$ bağının çift bağ karakteri gereği, hem deneysel hemde teorik sonuçlar incelendiğinde $\mathrm{C} 1=\mathrm{O} 18$ bağ uzunluğu C1-O17 bağ uzunluğundan oldukça kısadır. Deneysel ve teorik çalışmalarının farklı fazlarda yapıldığı göz önüne alındığında, genel olarak gözlemlenen farklılıklara rağmen deneysel ve teorik sonuçlar arasında iyi bir uyum olduğunu söyleyebiliriz. Deneysel ve teorik sonuçlar arasındaki bu farklılıklar, katı formdaki kristal yapıda moleküller arası etkileşimlerin oluşu ve teorik sonuçların ise gaz fazında tek bir molekül için hesaplanmasından kaynaklanmaktadır.

Tablo 1. POA'nın DFT/B3LYP/6-311++G(d,p) yöntemiyle optimize edilmiş geometrik parametrelerinin izomorfu olan OA'nın deneyselparametreleriyle karşılaştırılması.

\begin{tabular}{ccc}
\hline Geometrik Parametreler & Hesaplanan & Deneysel $^{*}$ \\
\hline Bağ Uzunlukları $(\AA)$ & & \\
C(1)=O(18) & 1,205 & 1,246 \\
C(1)-O(17) & 1,360 & 1,334 \\
C(1)-C(2) & 1,510 & 1,498 \\
C(2)-C(3) & 1,528 & 1,505 \\
C(3)-C(4) & 1,533 & 1,546 \\
C(4)-C(5) & 1,533 & 1,542 \\
C(5)-C(6) & 1,533 & 1,494 \\
C(6)-C(7) & 1,532 & 1,536 \\
C(7)-C(8) & 1,540 & 1,557 \\
C(9)-C(8) $(1)$ & 1,504 & 1,503 \\
\hline
\end{tabular}




\begin{tabular}{|c|c|c|}
\hline & $\begin{array}{l}\text { BŞEÜ Fen Bilimleri Dergisi } \\
7(2), 553-573,2020\end{array}$ & $\begin{array}{r}\text { BSEU Journal of Science } \\
\text { DOI: } 10.35193 / \text { bseufbd.741065 }\end{array}$ \\
\hline & & 58-7575 (http://dergipark.gov.tr/bseufbd) \\
\hline
\end{tabular}

\begin{tabular}{|c|c|c|}
\hline Geometrik Parametreler & Hesaplanan & Deneysel \\
\hline $\begin{array}{c}\text { Bağ Uzunlukları ( } \AA \text { ) } \\
\mathrm{C}(9)=\mathrm{C}(10) \\
\mathrm{C}(10)-\mathrm{C}(11) \\
\mathrm{C}(11)-\mathrm{C}(12) \\
\mathrm{C}(12)-\mathrm{C}(13) \\
\mathrm{C}(13)-\mathrm{C}(14) \\
\mathrm{C}(14)-\mathrm{C}(15) \\
\mathrm{C}(15)-\mathrm{C}(16) \\
\mathrm{O}(17)-\mathrm{H} \\
\mathrm{O} \ldots \ldots . \mathrm{H}\end{array}$ & $\begin{array}{l}1,337 \\
1,504 \\
1,540 \\
1,532 \\
1,533 \\
1,533 \\
1,532 \\
0,969 \\
2,288\end{array}$ & $\begin{array}{l}1,389 \\
1,513 \\
1,547 \\
1,564 \\
1,555 \\
1,502 \\
1,508 \\
1,158 \\
2,442\end{array}$ \\
\hline 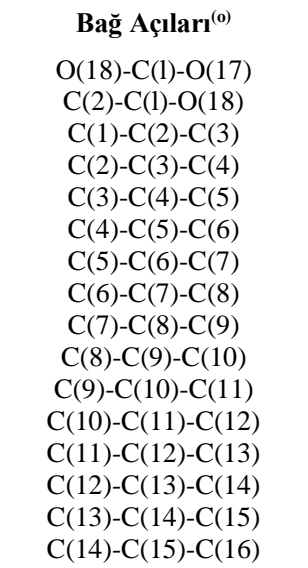 & $\begin{array}{l}122,2 \\
126,5 \\
113,8 \\
112,6 \\
113,2 \\
113,6 \\
113,5 \\
113,3 \\
112,8 \\
128,3 \\
128,4 \\
112,7 \\
113,4 \\
113,5 \\
113,7 \\
113,3\end{array}$ & $\begin{array}{l}119,4 \\
120,6 \\
115,6 \\
106,9 \\
111,2 \\
110,3 \\
112,2 \\
111,0 \\
105,8 \\
125,8 \\
125,6 \\
107,4 \\
110,7 \\
112,3 \\
114,2 \\
115,7\end{array}$ \\
\hline $\begin{array}{c}\text { Dihedral Açıları } \\
\text { O(1) } \\
\text { O(18)-C(1)-O(17)-H(52) } \\
\mathrm{C}(2)-\mathrm{C}(1)-\mathrm{O}(17)-\mathrm{H}(52) \\
\mathrm{C}(3)-\mathrm{C}(2)-\mathrm{C}(1)-\mathrm{O}(18) \\
\mathrm{C}(3)-\mathrm{C}(2)-\mathrm{C}(1)-\mathrm{O}(17) \\
\mathrm{C}(1)-\mathrm{C}(2)-\mathrm{C}(3)-\mathrm{C}(4) \\
\mathrm{C}(2)-\mathrm{C}(3)-\mathrm{C}(4)-\mathrm{C}(5) \\
\mathrm{C}(3)-\mathrm{C}(4)-\mathrm{C}(5)-\mathrm{C}(6) \\
\mathrm{C}(4)-\mathrm{C}(5)-\mathrm{C}(6)-\mathrm{C}(7) \\
\mathrm{C}(5)-\mathrm{C}(6)-\mathrm{C}(7)-\mathrm{C}(8) \\
\mathrm{C}(6)-\mathrm{C}(7)-\mathrm{C}(8)-\mathrm{C}(9) \\
\mathrm{C}(7)-\mathrm{C}(8)-\mathrm{C}(9)-\mathrm{C}(10) \\
\mathrm{C}(8)-\mathrm{C}(9)-\mathrm{C}(10)-\mathrm{C}(11) \\
\mathrm{C}(9)-\mathrm{C}(10)-\mathrm{C}(11)-\mathrm{C}(12) \\
\mathrm{C}(10)-\mathrm{C}(11)-\mathrm{C}(12)-\mathrm{C}(13) \\
\mathrm{C}(11)-\mathrm{C}(12)-\mathrm{C}(13)-\mathrm{C}(14) \\
\mathrm{C}(12)-\mathrm{C}(13)-\mathrm{C}(14)-\mathrm{C}(15) \\
\mathrm{C}(13)-\mathrm{C}(14)-\mathrm{C}(15)-\mathrm{C}(16)\end{array}$ & $\begin{array}{c}0,0 \\
-180,0 \\
0,2 \\
-179,8 \\
-179,7 \\
180,0 \\
180,0 \\
179,6 \\
179,6 \\
176,1 \\
119,3 \\
-0,2 \\
-122,6 \\
-176,9 \\
179,7 \\
-179,9 \\
179,8\end{array}$ & $\begin{array}{c}-17,2 \\
152,2 \\
-18,1 \\
151,3 \\
174,2 \\
-177,3 \\
177,3 \\
174,4 \\
179,9 \\
175,6 \\
132,4 \\
-1,8 \\
-127,5 \\
-171,2 \\
175,1 \\
178,5 \\
-176,9\end{array}$ \\
\hline
\end{tabular}

Tablo 1'deki sonuçlar incelendiğinde, hidrokarbon zinciri boyunca çift bağlı karbon içeren $(\mathrm{C}=\mathrm{C}-\mathrm{C}, \mathrm{C}$ $\mathrm{C}=\mathrm{C}$ ) bağ açıları $120^{\circ}$ ' den biraz büyük, diğerleri (C-C-C) ise $120^{\circ}$ 'den biraz küçüktür.

Teorik olarak hesaplanan ve deneysel olarak elde edilen geometrik parametreler (bağ uzunlukları, bağ açıları ve dihedral açıları) arasında korelasyon grafikleri çizilmiş ve korelasyon grafiklerinden korelasyon katsayıları $\left(R^{2}\right)$ bağ uzunlukları, bağ açıları ve dihedral açıları için sırasıyla $R^{2}=0,9409, R^{2}=0,8480$ ve $R^{2}=0,9623$ olarak elde edilmiştir. Bu değerler elde edilen teorik sonuçların deneysel verilerle oldukça uyumlu olduğunu göstermektedir. Ayrıca, teorik ve deneysel geometriler arasındaki uyumu görselleştirmek amacıyla POA' nın B3LYP/6-311++G(d,p) seviyesinde optimize edilmiş geometrik yapısı ve OA' nın X-ray kristal yapısının overlay diyagramı Şekil2'de gösterilmiştir. Bütün bunlara ek olarak POA'nın teorik olarak hesaplanan geometrik parametlerinin kristal yapısı bilenen Erüsik asit (cis-13-Docosenoic acid, C22:1) gibi benzer yapılara sahip tekli doymamış yă asitlerinin geometrik parametreleriyle kıyaslandığında, hidrokarbon zincir boyunca C-C-C-C 


\begin{tabular}{|c|c|c|}
\hline & $\begin{array}{l}\text { BŞEÜ Fen Bilimleri Dergisi } \\
7(2), 553-573,2020\end{array}$ & $\begin{array}{r}\text { BSEU Journal of Science } \\
\text { DOI: } 10.35193 / \text { bseufbd. } 741065\end{array}$ \\
\hline & & 58-7575 (http://dergipark.gov.tr/bseufbd) \\
\hline
\end{tabular}

dihedral, C-C-C bağ açıları ve C-C, bağ uzunluklarının deneysel sonuçlarla oldukça uyumlu olduğu görülmektedir [16,17].

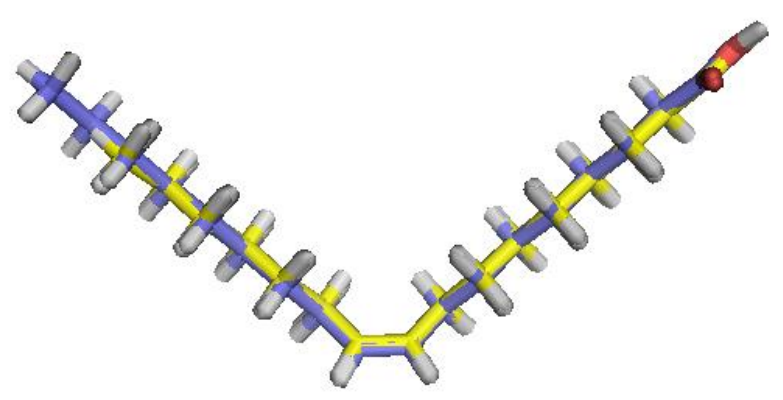

Şekil 2. POA' nın optimize geometrik yapısı (sarı) ve OA' nın X-ray kristal yapısının (mavi) overlay diyagramı

\section{B. Titreşimsel analiz}

POA molekülü 12 metilen $\left(\mathrm{CH}_{2}\right)$, bir metil $\left(\mathrm{CH}_{3}\right)$ ve bir karboksilik $(\mathrm{COOH})$ gruptan oluşurve 138 titreşim moduna sahiptir. Molekülün optimize olmuş geometrik parametreleri üzerinden DFT/B3LYP yöntemi ve 6-311G++(d,p) baz seti kullanılarak, tüm titreşim modları, onlara ait dalgasayısı ve IR şiddet değerleri hesaplanmıştır. POA' nındeneysel ATRFT-IR spektrumuliteratürden alınmış [18] ve spektrumdaki karakteristik bandların işaretlemesi yapılmıştır. DFT/B3LYP/6-311++G(d,p) seviyesinde harmonik yaklaşımla hesaplanan dalgasayıları ile deneysel dalgasayıları arasındaki farklılıkları azaltmak amacıyla, hesaplanan dalgasayıları, titreşim dalgasayılarının $1700 \mathrm{~cm}^{-1}$ 'e eşit veya daha büyük değerleri için 0,958 ile ve $1700 \mathrm{~cm}^{-1}$ 'in altındaki değerleri için 0,983 ile çarpılarak ölçeklendirilmiştir.

POA’ nın DFT/B3LYP/6-311++G(d,p) seviyesinde hesaplanan temel titreşim modlarına ait harmonik titreşim frekansları $\left(\mathrm{cm}^{-1}\right)$, infrared şiddetleri $(\mathrm{km} / \mathrm{mol})$, deneysel titreşim frekansları $\left(\mathrm{cm}^{-1}\right)$, titreşim modlarının PED (Potansiyel enerji katkısı) değerleri ve spektral işaretlemeleriTablo 2' de listelenmiştir.POA' nın teorik (ölçeklendirilmiş) infrared spektrumu ve deneysel ATR FT-IR spektrumu karşılaştırmalı olarak Şekil 3' te gösterilmiştir.Tartışma kolaylığı açısından $\mathrm{POA}^{\prime}$ nın temel titreşim modları $\mathrm{CH}_{3}$ (metil), $\mathrm{CH}_{2}$ (metilen), $\mathrm{C}=\mathrm{C}$ ve karboksil $(\mathrm{COOH})$ gruplarının gerilme ve bükülme titreşimleri grup frekansları göz önüne alınarak incelenmiştir.

Tablo 2. POA' nın B3LYP/6-311++G(d,p) seviyesinde hesaplanan harmonik titreşim frekanslarının $\left(\mathrm{cm}^{-1}\right)$ ve deneysel $(\mathrm{FT}-\mathrm{IR})$ titreşim frekansları ile karşılaştırması. $\mathrm{I}_{\mathrm{IR}}$ infrared şiddetleri $(\mathrm{km} / \mathrm{mol})$ ve titreşim modu işaretlemeleri.

\begin{tabular}{|c|c|c|c|c|}
\hline \multicolumn{3}{|c|}{ B3LYP/6-311++G(d,p) } & \multirow{2}{*}{$\begin{array}{c}\text { Deneysel } \\
\text { (FTIR) }^{\mathrm{a}}\end{array}$} & \multirow{2}{*}{$\frac{\text { Isşaretleme }^{\mathrm{b}}}{\operatorname{PED}^{\mathrm{c}}(\%)}$} \\
\hline Hesaplanan & Ölçeklendirilmiş & $\mathbf{I}_{\mathrm{IR}}$ & & \\
\hline 3759 & 3601 & 66 & & $v(\mathrm{OH})(100)$ \\
\hline 3124 & 2993 & 51 & 3007 & $v(\mathrm{CH})(98)$ \\
\hline 3100 & 2970 & 15 & & $v(\mathrm{CH})(96)$ \\
\hline 3082 & 2953 & 46 & & $v_{a}\left(\mathrm{CH}_{2}\right)(91)$ \\
\hline 3078 & 2949 & 80 & 2956 & $v_{\mathrm{a}}\left(\mathrm{CH}_{3}\right)(90)$ \\
\hline 3077 & 2948 & 60 & & $v_{\mathrm{a}}\left(\mathrm{CH}_{2}\right)(92)$ \\
\hline 3071 & 2942 & 48 & & $v_{\mathrm{a}}\left(\mathrm{CH}_{2}\right)(88)$ \\
\hline 3060 & 2932 & 57 & & $v_{\mathrm{a}}\left(\mathrm{CH}_{2}\right)(82)$ \\
\hline 3053 & 2924 & 24 & & $v_{\mathrm{a}}\left(\mathrm{CH}_{2}\right)(86)$ \\
\hline 3049 & 2921 & 63 & 2922 & $v_{\mathrm{a}}\left(\mathrm{CH}_{2}\right)(96)$ \\
\hline 3046 & 2918 & 29 & & $v_{\mathrm{a}}\left(\mathrm{CH}_{2}\right)(86)$ \\
\hline 3037 & 2909 & 42 & & $v_{\mathrm{a}}\left(\mathrm{CH}_{2}\right)(90)$ \\
\hline 3036 & 2909 & 7 & & $v_{\mathrm{a}}\left(\mathrm{CH}_{2}\right)(88)$ \\
\hline 3035 & 2907 & 0 & & $v_{\mathrm{a}}\left(\mathrm{CH}_{2}\right)(87)$ \\
\hline 3027 & 2900 & 3 & & $v_{\mathrm{s}}\left(\mathrm{CH}_{2}\right)(90)$ \\
\hline 3020 & 2893 & 7 & & $v_{\mathrm{a}}\left(\mathrm{CH}_{2}\right)(90)$ \\
\hline 3018 & 2891 & 5 & & $v_{\mathrm{a}}\left(\mathrm{CH}_{2}\right)(90)$ \\
\hline 3017 & 2891 & 52 & & $v_{\mathrm{s}}\left(\mathrm{CH}_{3}\right)(92)$ \\
\hline
\end{tabular}




\begin{tabular}{|c|c|c|}
\hline & $\begin{array}{l}\text { BŞEÜ Fen Bilimleri Dergisi } \\
7(2), 553-573,2020\end{array}$ & $\begin{array}{r}\text { BSEU Journal of Science } \\
\text { DOI: } 10.35193 / \text { bseufbd.741065 }\end{array}$ \\
\hline $\begin{array}{l}\text { BiLECCKS SEYH EDEBALI } \\
\text { UNIVERSITESI }\end{array}$ & & 58-7575 (http://dergipark.gov.tr/bseufbd) \\
\hline
\end{tabular}

\begin{tabular}{|c|c|c|c|c|}
\hline \multicolumn{3}{|c|}{ B3LYP/6-311++G(d,p) } & \multirow{2}{*}{$\begin{array}{c}\text { Deneysel } \\
\text { (FTIR) }^{\mathrm{a}}\end{array}$} & \multirow{2}{*}{$\frac{\text { İşaretleme }^{\mathrm{b}}}{\operatorname{PED}^{\mathrm{c}}(\%)}$} \\
\hline Hesaplanan & Ölçeklendirilmiş & $\mathbf{I}_{\mathrm{IR}}$ & & \\
\hline 3011 & 2885 & 40 & & $v_{\mathrm{a}}\left(\mathrm{CH}_{2}\right)(87)$ \\
\hline 3010 & 2884 & 98 & 2860 & $v_{s}\left(\mathrm{CH}_{2}\right)(93)$ \\
\hline 3009 & 2883 & 45 & & $v_{\mathrm{s}}\left(\mathrm{CH}_{2}\right)(89)$ \\
\hline 3008 & 2882 & 23 & & $v_{s}\left(\mathrm{CH}_{2}\right)(90)$ \\
\hline 3004 & 2878 & 0 & & $v_{s}\left(\mathrm{CH}_{2}\right)(87)$ \\
\hline 3002 & 2876 & 7 & & $v_{\mathrm{s}}\left(\mathrm{CH}_{2}\right)(88)$ \\
\hline 2995 & 2869 & 15 & & $v_{s}\left(\mathrm{CH}_{2}\right)(93)$ \\
\hline 2994 & 2868 & 7 & & $v_{s}\left(\mathrm{CH}_{2}\right)(91)$ \\
\hline 2993 & 2867 & 2 & & $v_{s}\left(\mathrm{CH}_{2}\right)(86)$ \\
\hline 2992 & 2867 & 5 & & $v_{\mathrm{s}}\left(\mathrm{CH}_{2}\right)(83)$ \\
\hline 2992 & 2866 & 9 & & $v_{s}\left(\mathrm{CH}_{2}\right)(87)$ \\
\hline 2989 & 2863 & 8 & & $v_{\mathrm{s}}\left(\mathrm{CH}_{2}\right)(89)$ \\
\hline 1812 & 1736 & 299 & 1703 & $v(\mathrm{C}=\mathrm{O})(89)$ \\
\hline 1715 & 1643 & 2 & 1658 & $v(\mathrm{C}=\mathrm{C})(72)+\rho(\mathrm{CH})(22)$ \\
\hline 1514 & 1489 & 17 & & $\delta\left(\mathrm{CH}_{2}\right)(84)$ \\
\hline 1513 & 1488 & 7 & & $\delta\left(\mathrm{CH}_{2}\right)(83)$ \\
\hline 1506 & 1481 & 1 & & $\delta\left(\mathrm{CH}_{2}\right)(81)$ \\
\hline 1505 & 1479 & 1 & & $\delta\left(\mathrm{CH}_{2}\right)(78)$ \\
\hline 1498 & 1473 & 8 & & $\delta\left(\mathrm{CH}_{2}\right)(90)$ \\
\hline 1497 & 1471 & 4 & & $\delta\left(\mathrm{CH}_{2}\right)(77)$ \\
\hline 1494 & 1469 & 1 & 1465 & $\delta\left(\mathrm{CH}_{2}\right)(79)$ \\
\hline 1490 & 1465 & 1 & & $\delta\left(\mathrm{CH}_{2}\right)(76)$ \\
\hline 1487 & 1462 & 0 & 1437 & $\operatorname{sciss}\left(\mathrm{CH}_{2}\right)(89)$ \\
\hline 1486 & 1461 & 0 & & $\delta\left(\mathrm{CH}_{2}\right)(78)$ \\
\hline 1486 & 1461 & 0 & & $\delta\left(\mathrm{CH}_{2}\right)(84)$ \\
\hline 1485 & 1460 & 0 & & $\delta\left(\mathrm{CH}_{2}\right)(76)$ \\
\hline 1478 & 1453 & 0 & & $\delta\left(\mathrm{CH}_{2}\right)(85)$ \\
\hline 1460 & 1435 & 16 & 1413 & $\delta\left(\mathrm{CH}_{2}\right)(92)$ \\
\hline 1440 & 1415 & 12 & & $\delta(\mathrm{CH})(70)$ \\
\hline 1417 & 1393 & 36 & & $\omega\left(\mathrm{CH}_{2}\right)(85)$ \\
\hline 1412 & 1388 & 2 & 1380 & $\delta\left(\mathrm{CH}_{3}\right)(93)$ \\
\hline 1403 & 1380 & 2 & & $\omega\left(\mathrm{CH}_{2}\right)(81)$ \\
\hline 1400 & 1376 & 1 & & $\omega\left(\mathrm{CH}_{2}\right)(79)$ \\
\hline 1395 & 1371 & 10 & & $\omega\left(\mathrm{CH}_{2}\right)(74)$ \\
\hline 1391 & 1367 & 1 & & $\omega\left(\mathrm{CH}_{2}\right)(83)$ \\
\hline 1372 & 1348 & 19 & & $\omega\left(\mathrm{CH}_{2}\right)(76)$ \\
\hline 1358 & 1335 & 5 & & $\omega\left(\mathrm{CH}_{2}\right)(74)$ \\
\hline 1340 & 1317 & 1 & & $\gamma\left(\mathrm{CH}_{2}\right)(82)$ \\
\hline 1339 & 1316 & 2 & & $\gamma\left(\mathrm{CH}_{2}\right)(81)$ \\
\hline 1337 & 1314 & 5 & & $\gamma\left(\mathrm{CH}_{2}\right)(77)$ \\
\hline 1336 & 1313 & 5 & & $\gamma\left(\mathrm{CH}_{2}\right)(72)$ \\
\hline 1329 & 1307 & 0 & & $t\left(\mathrm{CH}_{2}\right)(75)$ \\
\hline 1326 & 1303 & 0 & & $\gamma\left(\mathrm{CH}_{2}\right)(72)$ \\
\hline 1320 & 1298 & 1 & & $\gamma\left(\mathrm{CH}_{2}\right)(72)$ \\
\hline 1316 & 1294 & 1 & & $\gamma\left(\mathrm{CH}_{2}\right)(72)$ \\
\hline 1308 & 1286 & 1 & 1287 & $\omega\left(\mathrm{CH}_{2}\right)(77)$ \\
\hline 1302 & 1280 & 4 & & $\delta(\mathrm{COH})(76)$ \\
\hline 1299 & 1277 & 1 & & $\delta(\mathrm{CH})(70)$ \\
\hline 1281 & 1259 & 0 & 1248 & $\gamma\left(\mathrm{CH}_{2}\right)(77)$ \\
\hline 1275 & 1253 & 2 & & $\gamma\left(\mathrm{CH}_{2}\right)(65)$ \\
\hline 1273 & 1251 & 8 & & $\delta(\mathrm{COH})(75)+\omega\left(\mathrm{CH}_{2}\right)(23)$ \\
\hline 1247 & 1226 & 1 & & $\gamma\left(\mathrm{CH}_{2}\right)(65)$ \\
\hline 1236 & 1215 & 2 & & $\gamma\left(\mathrm{CH}_{2}\right)(65)$ \\
\hline 1234 & 1213 & 8 & & $\gamma\left(\mathrm{CH}_{2}\right)(65)$ \\
\hline 1220 & 1199 & 0 & & $\gamma\left(\mathrm{CH}_{2}\right)(62)$ \\
\hline 1181 & 1161 & 0 & & $\gamma\left(\mathrm{CH}_{2}\right)(67)+v(\mathrm{C}-\mathrm{C})(10)$ \\
\hline 1144 & 1125 & 134 & 1226 & $v(\mathrm{C}-\mathrm{O})(47)+\delta(\mathrm{COH})(31)$ \\
\hline 1142 & 1122 & 121 & & $\gamma\left(\mathrm{CH}_{2}\right)(62)$ \\
\hline 1132 & 1112 & 2 & & $\gamma\left(\mathrm{CH}_{2}\right)(64)$ \\
\hline 1110 & 1091 & 4 & & $\gamma\left(\mathrm{CH}_{2}\right)(65)$ \\
\hline 1098 & 1079 & 63 & & $\delta(C C C)(42)+v(C-C)(17)+v(C-O)$ \\
\hline 1067 & 1049 & 1 & & $v(C-C)(49)+\mathrm{t}\left(\mathrm{CH}_{2}\right)(18)+\delta(\mathrm{CH})(10)$ \\
\hline 1064 & 1046 & 3 & & $v(C-C)(76)$ \\
\hline 1062 & 1044 & 2 & & $v(C-C)(69)$ \\
\hline 1054 & 1037 & 8 & & $v(C-C)(48)+\delta(C H)(10)$ \\
\hline
\end{tabular}




\begin{tabular}{|c|c|c|}
\hline & $\begin{array}{l}\text { BŞEÜ Fen Bilimleri Dergisi } \\
7(2), 553-573,2020\end{array}$ & $\begin{array}{r}\text { BSEU Journal of Science } \\
\text { DOI: } 10.35193 / \text { bseufbd.741065 }\end{array}$ \\
\hline $\begin{array}{l}\text { Le } \\
\text { R }\end{array}$ & & 58-7575 (http://dergipark.gov.tr/bseufbd) \\
\hline
\end{tabular}

\begin{tabular}{|c|c|c|c|c|}
\hline \multicolumn{3}{|c|}{ B3LYP/6-311++G(d,p) } & \multirow{2}{*}{$\begin{array}{c}\text { Deneysel } \\
\text { (FTIR) }^{\mathrm{a}}\end{array}$} & \multirow{2}{*}{$\frac{\text { Isșaretleme }^{\mathrm{b}}}{\text { PED }^{\mathrm{c}}(\%)}$} \\
\hline Hesaplanan & Ölçeklendirilmiş & $\mathbf{I}_{\mathrm{IR}}$ & & \\
\hline 1062 & 1044 & 2 & & $v(C-C)(69)$ \\
\hline 1054 & 1037 & 8 & & $v(C-C)(48)+\delta(C H)(10)$ \\
\hline 1046 & 1028 & 3 & & $v(C-C)(42)+\delta(C H)(25)$ \\
\hline 1043 & 1025 & 11 & & $v(\mathrm{C}-\mathrm{C})(58)+\gamma(\mathrm{CH})$ \\
\hline 1025 & 1008 & 5 & & $v(\mathrm{C}-\mathrm{C})(60)+\gamma(\mathrm{CH})(23)$ \\
\hline 1017 & 1000 & 4 & & $\gamma(\mathrm{CH})(74)+\delta(C C C)(17)$ \\
\hline 1016 & 999 & 4 & & $v(\mathrm{C}-\mathrm{C})(60)+\gamma(\mathrm{CH})(23)$ \\
\hline 1009 & 992 & 4 & & $\gamma(\mathrm{CH})(60)$ \\
\hline 1003 & 986 & 2 & & $v(C-C)(62)$ \\
\hline 998 & 981 & 0 & & $v(C-C)(37)+\gamma\left(C_{2}\right)(16)$ \\
\hline 984 & 968 & 1 & & $\gamma\left(\mathrm{CH}_{2}\right)(58)$ \\
\hline 939 & 923 & 2 & & $v(C-C)(48)+(C C=C C)(25)$ \\
\hline 913 & 898 & 3 & & $\rho\left(\mathrm{CH}_{2}\right)(40)+\gamma(\mathrm{CH})$ \\
\hline 896 & 881 & 1 & & $v(\mathrm{C}-\mathrm{C})(34)+\rho\left(\mathrm{CH}_{3}\right)(28)$ \\
\hline 891 & 875 & 2 & & $v(C-C)(40)+\rho\left(C_{3}\right)(25)$ \\
\hline 878 & 863 & 3 & & $v(C-C)(59)+v(C-O)$ \\
\hline 836 & 821 & 5 & & $\gamma\left(\mathrm{CH}_{2}\right)(69)$ \\
\hline 801 & 788 & 2 & & $\rho\left(\mathrm{CH}_{2}\right)(72)$ \\
\hline 773 & 760 & 3 & & $\gamma\left(\mathrm{CH}_{2}\right)(70)$ \\
\hline 747 & 734 & 5 & & $\rho\left(\mathrm{CH}_{2}\right)(72)$ \\
\hline 739 & 726 & 7 & 727 & $\rho\left(\mathrm{CH}_{2}\right)(75)$ \\
\hline 732 & 719 & 2 & & $\rho\left(\mathrm{CH}_{2}\right)(72)$ \\
\hline 731 & 719 & 6 & & $\rho\left(\mathrm{CH}_{2}\right)(72)$ \\
\hline 727 & 715 & 27 & & $\gamma(\mathrm{CH})(67)+\rho\left(\mathrm{CH}_{2}\right)(12)$ \\
\hline 650 & 639 & 86 & & $\tau(\mathrm{COOH})(86)$ \\
\hline 637 & 626 & 25 & 632 & $\delta(O C O)(71)+v(C-O)(16)$ \\
\hline 598 & 588 & 6 & 602 & $\delta(C C C)(32)+v(C-C)(15)+\gamma\left(C_{2}\right)(11)$ \\
\hline 543 & 533 & 9 & & $\delta(\mathrm{CCC})(53)+\gamma\left(\mathrm{CH}_{2}\right)(13)$ \\
\hline 520 & 511 & 28 & & $\tau(\mathrm{CCOH})(78)$ \\
\hline 515 & 507 & 11 & & $\delta(C C O)(63)$ \\
\hline 458 & 450 & 1 & & $\delta(C C C)(59)$ \\
\hline 445 & 437 & 2 & & $\delta(C C C)(61)$ \\
\hline 411 & 404 & 4 & & $\delta(C C C)(56)+\delta(C C O)(20)$ \\
\hline 382 & 376 & 2 & & $\delta(C C C)(61)+v(C-C)(12)$ \\
\hline 309 & 303 & 0 & & $\delta(C C C)(53)+\tau(C C=C H)(12)$ \\
\hline 305 & 300 & 1 & & $\delta(C C C)(57)$ \\
\hline 263 & 258 & 0 & & $\delta(C C C)(50)+\tau(\mathrm{CCCH})(13)$ \\
\hline 238 & 234 & 0 & & $\tau\left(\mathrm{CH}_{3}\right)(92)$ \\
\hline 217 & 213 & 1 & & $\delta(C C C)(53)+v(C-C)(10)$ \\
\hline 201 & 198 & 0 & & $\delta(C C C)(43)+\tau(C C C C)(15)$ \\
\hline 176 & 173 & 0 & & $\tau(C C C C)(38)+\delta(C C C)(26)+v(C-C)(10)$ \\
\hline 155 & 152 & 0 & & $\tau(C C C C)(57)$ \\
\hline 152 & 149 & 0 & & $\tau(C C C C)(57)$ \\
\hline 142 & 140 & 0 & & $\tau(C C C C)(57)$ \\
\hline 132 & 130 & 0 & & $\tau(C C C C)(66)$ \\
\hline 117 & 115 & 1 & & $\delta(C C C)(59)$ \\
\hline 103 & 102 & 0 & & $\delta(C C C)(62)$ \\
\hline 97 & 95 & 0 & & $\tau(\mathrm{CCCH})(58)+\tau(\mathrm{CCCC})(13)$ \\
\hline 81 & 79 & 0 & & $\tau(\mathrm{HCCH})(56)$ \\
\hline 76 & 74 & 0 & & $\tau(C C C C)(73)$ \\
\hline 53 & 52 & 0 & & $\tau(\mathrm{CCCH})(55)+\tau(\mathrm{OCCC})(23)+\tau\left(\mathrm{CH}_{3}\right)(10)$ \\
\hline 49 & 48 & 0 & & $\tau(C C C H)(56)+\tau(C C C C)(15)+\tau(O C C C)(10)$ \\
\hline 43 & 42 & 0 & & $\tau(C C C C)(42)+\tau(C C C H)(26)$ \\
\hline 37 & 36 & 0 & & $\tau(C C C C)(67)$ \\
\hline 26 & 26 & 0 & & $\tau(C C C C)(72)$ \\
\hline 19 & 19 & 2 & & $\tau(C C C O)(62)+\tau(C C C C)(23)+(C C C H)(12)$ \\
\hline 8 & 8 & 0 & & $\tau(C C C C)(77)$ \\
\hline
\end{tabular}

${ }^{\mathrm{a} R e f[18]}$

${ }^{\text {b} T i t r e s ̦ i m ~ t u ̈ r l e r i: ~} v$; gerilme, $\mathrm{s}$; simetrik, a; asimetrik, $\delta$; deformasyon, sciss; makaslama, $\gamma$; düzlemdışı bükülme, $\omega$; dalgalanma, $\rho$; sallanma, t;kıvirma, $\mathrm{T}$; torsiyon

'PED; Normal modların potansiyel enerji katkısı. \%10' un altındaki PED’ler dahil değildir. 


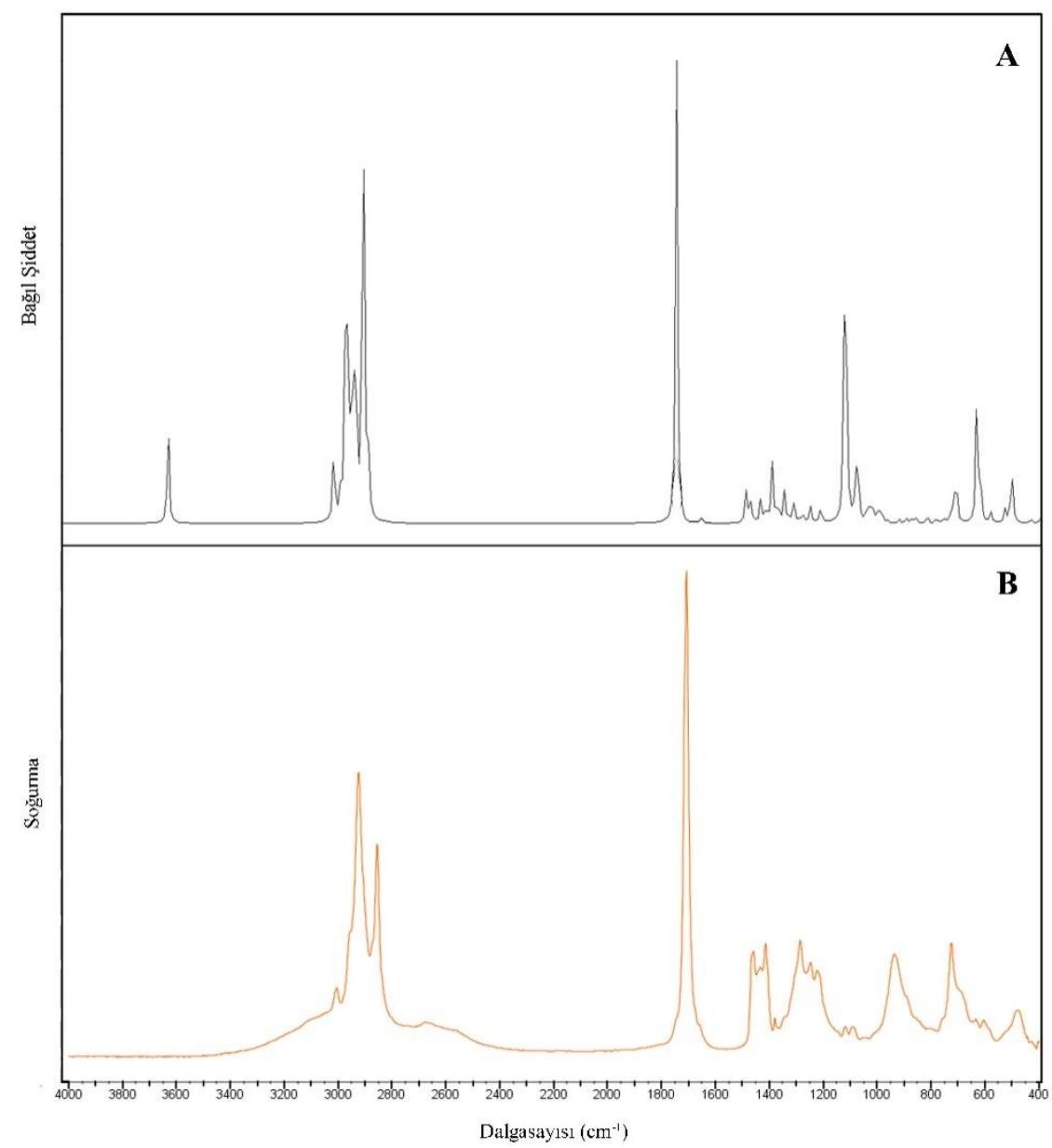

Şekil 3. POA’ nın A)gaz fazındaki teorik IR spektrumu B) sıvı formdaki ATR FT-IR spektrumu

Doymamış yağ asitleri zincirindeki çift bağlara bağlı olan C-H grubunun bağ gerilme titreşim moduna ait $v(\mathrm{CH})$ bandı infrared spektrumda $3000 \mathrm{~cm}^{-1}$ 'e yakın bir bölgede gözlenir. POA'nın FT-IR spektrumunda $3007 \mathrm{~cm}^{-1}$ 'de işaretlenen band, cis konfigürasyondaki çift $\mathrm{C}=\mathrm{C}$ bağına bağlı olan $\mathrm{C}-\mathrm{H}^{\prime}$ lar için $v(\mathrm{CH})$ gerilme titreşim moduna ait banttır[19]. Bu band deneysel spektrumda $3007 \mathrm{~cm}^{-1}$ 'de işaretlenirken teorik (ölçeklendirilmiş) spektrumda ise $2993 \mathrm{~cm}^{-1}$ olarak hesaplanmıştır.

$\mathrm{CH}$ gerilme bölgesindeki spektral özellikler, $\mathrm{CH}_{2}$ bakımından zengin moleküllerin spektral analizinde çok faydalıdır, çünkü bu özellikler faz geçişi ile dramatik bir şekilde değişirler. Metilen gruplarının gerilme titreşimleri 2800-3000 $\mathrm{cm}^{-1}$, lik bölgeye yayılmış çok karmaşık bir bantta bulunur. $\mathrm{CH}_{2}$ grubun asimetrik ve simetrik gerilme titreşimleri deneysel FT-IR spektrumunda sırasıyla $2922 \mathrm{~cm}^{-1}$ ve $2860 \mathrm{~cm}^{-1}$ olarak işaretlenirken, teorik spektrumda sırasıyla $2921 \mathrm{~cm}^{-1}$ ve $2884 \mathrm{~cm}^{-1}$ olarak hesaplanmıştır. POA'nın FT-IR spektrumunda $1465 \mathrm{~cm}^{-1}$, de gözlenen band $\delta\left(\mathrm{CH}_{2}\right)$ düzlem içi açı bükülme modu olarak işaretlenmiş, teorik spektrumda $1469 \mathrm{~cm}^{-1}$ ' de hesaplanmıştır. FT-IR spektrumunda $1413 \mathrm{~cm}^{-1}$ 'de işaretlenen band ise, COOH grubuna komşu olan $\mathrm{CH}_{2}$ grubuna ait $\delta\left(\mathrm{CH}_{2}\right)$ düzlem içi açı bükülme modu olarak işaretlenirken,teorik spektrumda $1435 \mathrm{~cm}^{-1}$ olarak hesaplanmıştır.

Metilen grup sallanma titreşimleri lipidlerin deneysel spektrumunda genellikle $720 \mathrm{~cm}^{-1}$ civarında gözlenir. $\rho\left(\mathrm{CH}_{2}\right)$ sallanma modu POA'nın deneysel spektrumunda $727 \mathrm{~cm}^{-1}$ 'de olarak işaretlenirken, bu mod teorik spektrumda $726 \mathrm{~cm}^{-1}$ olarak hesaplanmıştır. 
$\mathrm{CH}_{3}$ grubunun simetrik ve asimetrik gerilme titreşimleri genel olarak 2800-3000 $\mathrm{cm}^{-1}$ dalgasayısı bölgesinde gözlenmektedir. POA'nın deneysel spektrumunda metil grubuna ait $v_{\mathrm{a}}\left(\mathrm{CH}_{3}\right)$ asimetrik gerilme titreşim modu $2956 \mathrm{~cm}^{-1}$, de işaretlenirken, teorik spektrumda $2949 \mathrm{~cm}^{-1}$ olarakhesaplanmıştır. Teorik spektrumda $2890 \mathrm{~cm}^{-1}$, de hesaplanan $v_{\mathrm{s}}\left(\mathrm{CH}_{3}\right)$ simetrik gerilme titreşim modu, bu bölgedeki diğer C-H modları tarafından perdelenmiş deneysel spektrumda işaretlenememiştir.

Metil grup asimetrik bükülme modu yağ asitlerinde yaklaşık $1460 \mathrm{~cm}^{-1}$ civarında gözlenir. $\delta\left(\mathrm{CH}_{3}\right)$ asimetrik bükülme modu $1473 \mathrm{~cm}^{-1}$ olarak hesaplanmıştır. Deneysel ATR FT-IR spektrumunda $\delta\left(\mathrm{CH}_{3}\right)$ simetrik bükülme modu ise $1380 \mathrm{~cm}^{-1}$ ' de gözlenmiş, teorik spektrumda bu mod $1388 \mathrm{~cm}^{-1}$ olarak hesaplanmıştır. Metil grup burulma modu $\tau(\mathrm{CH} 3)$ deneysel spektrumda genellikle $240 \mathrm{~cm}^{-1}$ civarında gözlenir ancak genel olarak düşük IR şiddetine sahiptir. POA'nın teorik spektrumunda bu mod $234 \mathrm{~cm}^{-1}$ olarak hesaplanmıştır.

Bir karboksilik asit, aynı karbon atomuna bağlı bir hidroksil grubuna $(\mathrm{OH})$ sahip bir karbonil grubu $(\mathrm{C}$ $=\mathrm{O})$ içeren bir fonksiyoneldir. Bu nedenle karboksilik asitlerin infrared spektrumlarında bu grubun $\mathrm{CO}, \mathrm{COH}$ ve $\mathrm{OH}$ titreşimleri beklenir [20]. Moleküle bağlı hidroksil grubuna ait $v(\mathrm{OH})$ gerilme band $13600-3200 \mathrm{~cm}^{-1}$ spektral aralığında gözlenir. Bu mod POA' nın teorik spektrumunda $3601 \mathrm{~cm}^{-1}$ olarak hesaplanırken, deneysel FT-IR spektrumunda gözlenememiştir. $\mathrm{Bu}$ durum dimerlerin $\mathrm{COOH}$ grupları arasındaki hidrojen bağı ile açıklanır. Karboksilik asitlerin genel olarak, güçlü dimerik kompleksler oluşturduğu bilinmektedir [21]. Karboksilik asitlerdeki hidrojen bağları oldukça güçlü olup özellikle sıvı fazda moleküller dimer yapıda birbirine bağlanmıştır. Deneysel FT-IR spektrumunda O-H gerilme titreşim moduna ait titreşim bandının gözlenmemesi ve $938 \mathrm{~cm}^{-1}$ 'de $\gamma(\mathrm{OH})$ düzlem dışı açı bükülme bandının gözlenmesi (Tablo 2' de $\tau(\mathrm{CO} . . \mathrm{OH})$ burulma titreşim modu), POA moleküllerinin dimer yapıda birbirine H-bağı ile bağlandığını göstermektedir.

$v(\mathrm{C}=\mathrm{O})$ gerilme bandı, molekülün fiziksel durumuna, komşu yerleşimlerin elektronik etkilerine, konjugasyona, molekül içi ve moleküller arası hidrojen bağına bağlı olarak $1870-1540 \mathrm{~cm}^{-1}$ bölgesinde gözlenir[22]. Bu titreşim modu, karboksilik asitlerin infrared spektrumlarında $1760-1690 \mathrm{~cm}^{-1}$ aralığında gözlenen şiddetli bir banttır. Karboksilik grubun karakteristik titreşimi olan $v(\mathrm{C}=\mathrm{O})$ gerilme modu $1736 \mathrm{~cm}^{-1}$ olarak hesaplanmıştır ve spektrumdaki en şiddetli moddur. $\mathrm{Bu}$ mod deneysel spektrumda $1703 \mathrm{~cm}^{-1} \mathrm{de}^{\prime}$ işaretlenen spektrumun en yüksek şiddetli modudur. Deneysel spektrumda bu modun teorik spektrumda işaretlenenden daha düşük dalgasayılarına kaymasının sebebi, sıvı formda dimerler arasında oluşan moleküller arası hidrojen bağıdır.Karboksilik asit dimer yapı titreşim spektrumlarında 1210-1320 $\mathrm{cm}^{-1}$ bölgesinde gözlenen $v(\mathrm{C}-\mathrm{O})$ gerilme modu, POA'nın deneysel FT-IR spektrumunda moleküler arası hidrojen bağı sebebiyle teorik spektruma göre daha yüksek dalgasayısında $1226 \mathrm{~cm}^{-1}$ 'de işaretlenmiştir. $\mathrm{Bu}$ mod, $1125 \mathrm{~cm}^{-1}$ olarak hesaplanmıştır. $v(\mathrm{C}-\mathrm{O})$ gerilmesi düzlem içi $\delta(\mathrm{COH})$ bükülme titreşimi ile karışık moddur.PED hesaplamaları bunun karışık bir mod olduğunu ortaya koymaktadır. Bu modun \% 47' si v(C-O) gerilmesi ve \% 31'lik düzlem içi $\delta(\mathrm{COH})$ açı bükülmesinden kaynaklanmaktadır.

$\delta(\mathrm{OCO})$ düzlemiçi açı bükülme modu teorik spektrumda $\mathrm{cm}^{-1}$ olarak hesaplanmıştır POA' nın ATRFTIR spektrumunda $632 \mathrm{~cm}^{-1}$ ' de gözlenen band, $\delta(\mathrm{OCO})$ modu olarak işaretlenmiştir.

$v(C=C)$ gerilme titreşimleri alifatik hidrokarbon zincirlerinde 1680-1600 $\mathrm{cm}^{-1}$ bölgesinde gözlenir. $v(\mathrm{C}=\mathrm{C})$ gerilme titreşim bandı, deneysel FT-IR spektrumunda $v(\mathrm{C}=\mathrm{O})$ şiddetli bandının yanında çok az şiddette, $1658 \mathrm{~cm}^{-1}$, de bir omuz titreşimi olarak gözlenirken, teorik analiz sonuncu $1643 \mathrm{~cm}^{-1}$ olarak hesaplanmıştır.

\section{Elektronik Özellikler}

Moleküler etkileşimde, birbirleriyle etkileşen iki önemli yörünge vardır. Bunlardan birincisi HOMO elektron verme yeteneğini temsil ederken, diğeri elektron alıcısı olan LUMO’ dur. Bu orbitallere molekülün sınır orbitalleri denir ve bir molekülün kimyasal kararlılığını, reaktivitesini anlamanın temelini oluşturması nedeniyle oldukça önemlidir. Orbitaller, elektron yoğunluğu hakkında da bilgi sağlar ve bu da molekülün hangi kısmının bir enerji transfer olayına en aktif şekilde katıldığını belirlemede kullanılır [23].

HOMO ve LUMO enerjileri arasındaki enerji farkına $(\Delta \mathrm{E})$ enerji aralığı denir ve molekülün kimyasal kararlılığının belirlenmesinde önemli bir faktördür. Molekül orbitallerinin enerji seviyeleri birbirine ne kadar yakınsa, yani HOMO-LUMO enerji aralığı ne kadar küçük ise molekül içinde elektronik transferler ve reaktantların reaksiyona girmesi de o kadar kolay olacaktır. Kısacası en küçük HOMO-LUMO boşluğuna sahip 
molekül daha reaktiftir. HOMO-LUMO enerji aralığının daha büyük olması ise molekülün kimyasal olarak daha kararlı olduğu anlamına gelmektedir [24].

Kimyasal sertlik ve yumuşaklık ise diğer önemli elektronik parametreler içinde ilk sıralarda yer alır. $\mathrm{Bu}$ parametreler kimyasal reaksiyon için büyük önem taşır ve kimyasal kararlılığınınbir ölçütüdür.Kimyasal sertlik ( ) ve yumuşaklık (S), HOMO ve LUMO enerjilerinden aşağıdaki eşitlikler kullanılarak hesaplanabilir [25].

$$
\begin{gathered}
\eta=\frac{\Delta E}{2} \\
S=\frac{1}{\eta}
\end{gathered}
$$

Molekülün büyük HOMO-LUMO boşluğu onun kimyasal olarak sert bir molekül olduğu ve küçük HOMO-LUMO boşluğu ise yumuşak bir molekül olduğu anlamına gelir[26].Daha düşük sertlik değeri daha yüksek reaktiviteye işaret eder, bu da küçük bir HOMO-LUMO aralığına sahip bir molekülün daha reaktif ve daha yumuşak olduğu anlamına gelir.Koopmans [27]teoremine göre, kimyasal bileşiklerin HOMO enerjisi doğrudan iyonizasyon potansiyeli (I) ile ilişkili iken, LUMO enerjisi ise doğrudan elektron affinitesi (A) ile ilişkilidir. Pozitif elektron afinitesine sahip bir molekül veya atom, elektron alıcısı olarak adlandırılır ve yük transfer reaksiyonlarına maruz kalabilir. Ayrıca bir molekülün elektron verme gücü, bir elektronun HOMO' dan uzaklaştırılması için gerekli enerji olan iyonizasyon potansiyeli ile ölçülür. İyonizasyon potansiyeli ve elektron afinitesi aşağıdaki eşitlikler ile hesaplanır.

$$
\begin{aligned}
& \mathrm{I}=-\mathrm{E}_{\text {номо }} \\
& \mathrm{A}=-\mathrm{E}_{\text {LUмо }}
\end{aligned}
$$

Elektronegatiflik $(\chi)$, bir atomun veya fonksiyonel grubun elektronları veya elektron yoğunluğunu kendisine çekme yeteneğini tanımlayan kimyasal bir özelliktir ve aşağıdaki bağıntı yardımıyla hesaplanmıştır.

$$
\chi=(\mathrm{I}+\mathrm{A}) / 2
$$

Elektrofililik indeksi $(\omega)$, moleküler sistem çevreden ek bir elektronik yük aldığında enerjideki kararlılığ ölçüsüdür[28]. Fiziksel olarak, kimyasal potansiyel $(\mu)$ dengeki bir sistemden elektronların ayrılma eğilimini ifade eder[29]. Kimyasal potansiyel ne kadar büyük olursa, bileşik o kadar az kararlı veya daha reaktiftir. Hem molekül içindeki elektron transferi hem de kararlılık hakkında bilgi içeren kimyasal potansiyel ve elektrofilik indeksi aşağıdaki şekilde hesaplanır.

$$
\begin{gathered}
\mu=-(\mathrm{I}+\mathrm{A}) / 2 \\
\omega=\mu^{2} / 2 \eta
\end{gathered}
$$

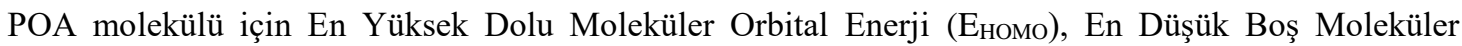
Orbital Enerjisi ( $\left.\mathrm{E}_{\mathrm{LUMO}}\right)$, Enerji aralı̆ $\mathrm{s}(\Delta \mathrm{E})$, elektronegatiflik $(\chi)$, kimyasal potansiyel $(\mu)$, kimyasal sertlik $(\eta)$ ve yumuşaklık (S), iyonizasyon potansiyeli (I), elektron afinitesi (A), elektrofik indeksi ( $\omega$ ) ve dipol moment gibi kuantum kimyasal tanımlayıcıları, B3LYP/6-311++G(d,p) seviyesinde hesaplanmış ve Tablo 3'de sunulmuştur. 


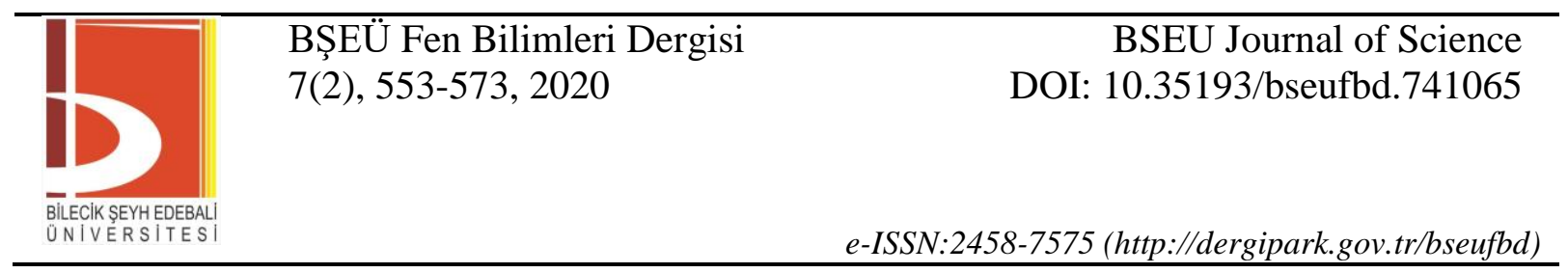

Tablo 3. POA'nın gaz fazında B3LYP/6-311++G(d,p) seviyesinde hesaplanmış kuantum kimyasal tanımlayıcıları.

\begin{tabular}{cc}
\hline Parametre & Değeri \\
\hline E $_{\text {Hомо }}(\mathrm{eV})$ & $-6,732$ \\
$\mathrm{E}_{\text {LUMо }}(\mathrm{eV})$ & $-0,402$ \\
$\Delta \mathrm{E}(\mathrm{eV})$ & 6,330 \\
İyonizasyon potansiyeli $(\mathrm{I})(\mathrm{eV})$ & 6,732 \\
Elektron affinitesi $(\mathrm{A})(\mathrm{eV})$ & 0,402 \\
Kimyasal potansiyel $(\mu)$ & $-3,567$ \\
Elektronegatiflik $(\chi)(\mathrm{eV})$ & 3,567 \\
Sertlik $(\eta)$ & 3,165 \\
Yumuşaklık $(\mathrm{S})\left(\mathrm{eV}{ }^{-1}\right)$ & 0,316 \\
Dipol Moment $\left(\operatorname{Debye}^{-1}\right)$ & 1,820 \\
Elektrofilik indeksi $(\omega)$ & 2,010 \\
\hline
\end{tabular}

Bileşiğin HOMO ve LUMO diyagramı Şekil 4' te gösterilmiştir. Buna göre, HOMO orbitallerinin elektron yoğunluğu molekülün çift bağı üzerinde yoğunlaşırken, LUMO orbitalinde elektron yoğunluğu karboksilik asit grubu üzerindedir.

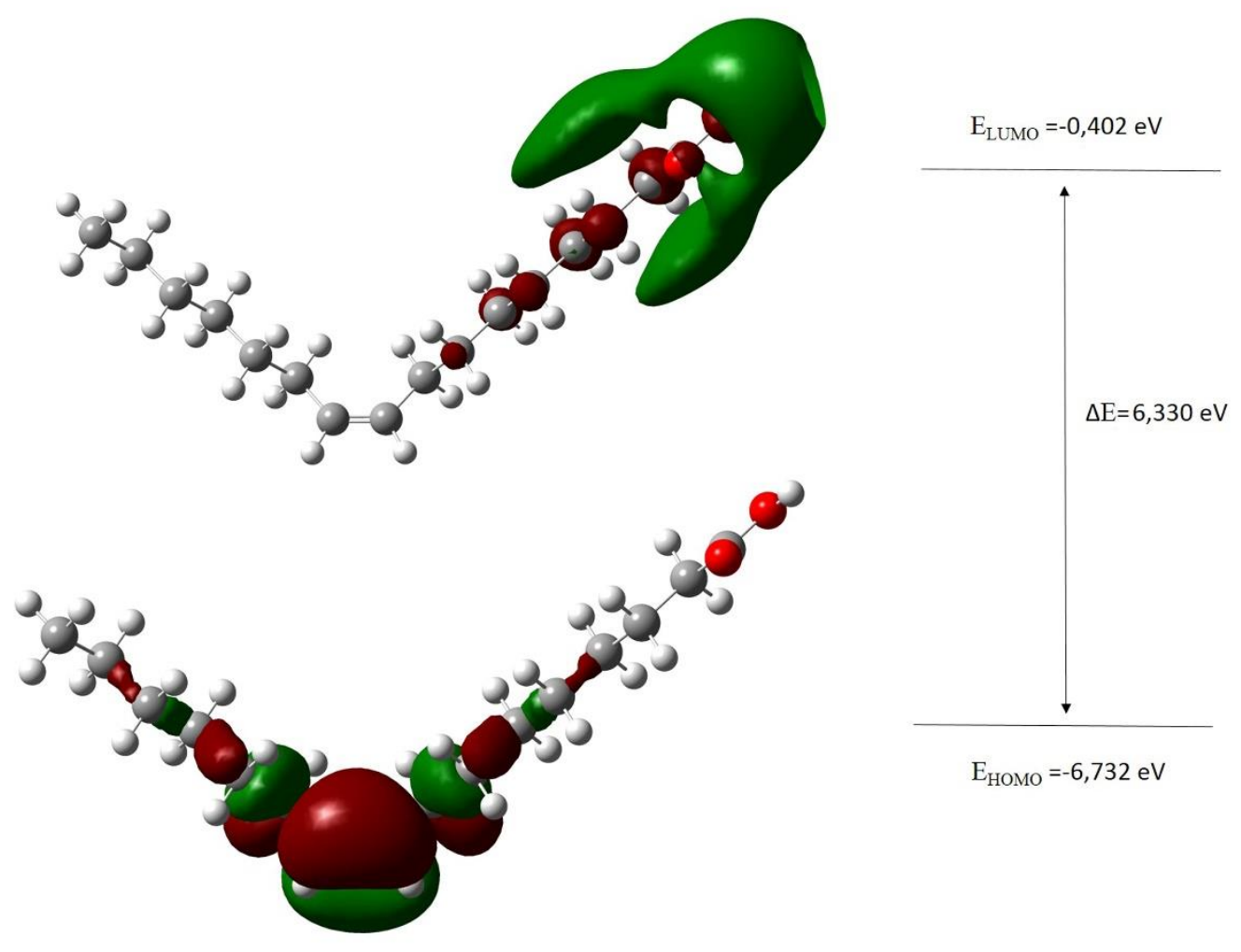

Şekil 4. POA molekülününmoleküler orbital (HOMO ve LUMO) diyagramı ve $\Delta \mathrm{E}$ enerji aralığı

POA molekülünün gaz fazında DFT/B3LYP/6-311++G(d,p) seviyesinde hesaplanan HOMO ve LUMO enerjisi sirasılyla $-6,732 \mathrm{eV}$ ve $-0,402 \mathrm{eV}$ ' dir. Buna göre $6,330 \mathrm{eV}$ değerindeyüksekolarak elde edilen HOMOLUMO enerji aralığı, POA bileşiğinin yüksek kimyasal kararlılı̆̆a ve düşük reaktiviteye sahip olduğunu gösterir. Tablo 3' teki sonuçlara göre elektrofilik indeksinin ve kimyasal potansiyelin sırasıyla 2,010 ve $-3,567$ eV olarak 
hesaplanan değeri, POA'nın kimyasal aktivitesini etkileyen molekül içindeki nihai yük transferi etkileşimini açılar.

\section{Moleküler Elektrostatik Potansiyel (MEP)}

Moleküler elektrostatik potansiyel (MEP) analizi, biyomoleküller ve ilaçlar da dahil olmak üzere moleküler sistemlerin yük dağılımlarını üç boyutlu olarak gösteren ve kimyasal reaktiviteleri, hidrojen bağı etkileşimleri, elektrofilik ve nükleofilik bölgeleri tayin etmek için sıklıkla kullanılan yararlı bir yöntemdir[30].

MEP moleküler boyut, şekil ve pozitif, negatif, nötr elektrostatik potansiyel bölgeleri aynı anda göstermesi ve fizikokimyasal özellik-moleküler yapı ilişkisinin araştırılmasında oldukça önemlidir[31]. Elde edilen yüzey, moleküler boyut ve şekil ile aynı anda elektrostatik potansiyel değerini gösterir.Ayrıca MEP, molekülün dipol momenti, elektronegatifliği, kısmi yükleri ve kimyasal reaktivite bölgesi ile ilişkilidir. Bir molekülün relatif polaritesini anlamak için görsel bir yöntem săglar.

Pozitif elektrostatik potansiyel, düşük elektron yoğunluğunun bulunduğu bölgelerde protonun atom çekirdeği tarafından itilmesine karşılık gelirken, negatif elektrostatik potansiyel molekülün konsantre elektron yoğunluğu ile protonun çekilmesine karşıllk gelir. MEP yüzeyindeki farklı elektrostatik potansiyel değerleri farklı renklerle temsil edilir: kırmızı, mavi ve yeşil en negatif, en pozitif ve sıfır elektrostatik potansiyeli olan bölgelerdir. Bu bölgelerin belirlenmesi, molekül içi ve moleküller arası etkileşim alanların belirlenmesi anlamına gelir.

Potansiyeldeki artışlar kırmızı <turuncu $<$ sarı <yeşil <mavi sırasıyla tanımlanır. Elektrostatik potansiyelin değeri, bir substratın reseptör bağlanma bölgelerine bağlanmasından büyük ölçüde sorumludur, çünkü reseptör ve karşıllık gelen ligandlar molekül yüzeylerinde birbirlerini tanırlar. Şekil 5, mevcut bileşik için B3LYP/6-311++G(d,p) yöntemi ile gaz fazında hesaplanan MEP yüzeyini göstermektedir. POA' nın MEP haritasının renk kodu $-5,435 \mathrm{eV}$ ve $+5,435 \mathrm{eV}$ arasında değişmektedir, burada mavi en güçlü çekiciliği ve kırmızı ise en güçlü iticiliği göstermektedir.

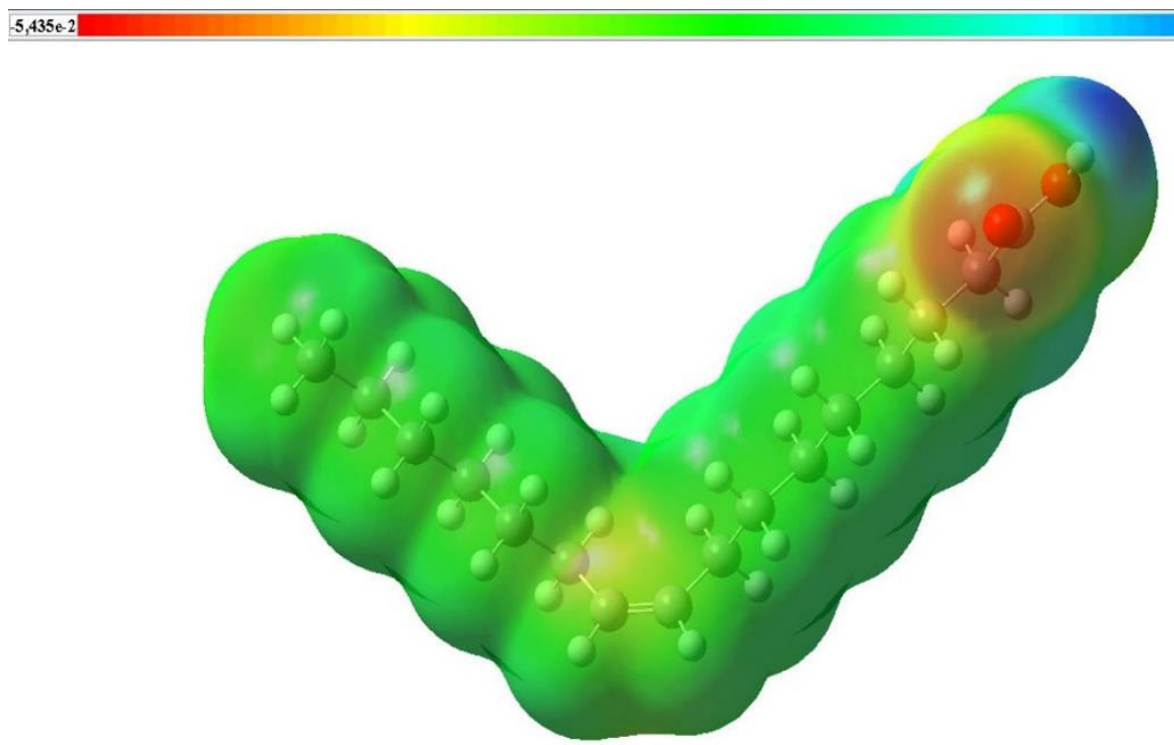

Şekil 5. POA için $\rho(r)=0,0004$ au üzerinde eşlenen moleküler elektrostatik potansiyel, $-5,435 \mathrm{e}-2$ (kırmızı) ile $+5,435 \mathrm{e}-2$ (mavi) arasında değişen izodensite yüzeyi

Şekil 5 kimyasal olarak aktif bölgenin görsel bir temsilini ve atomlardaki relatif reaktiviteyi sunmaktadır[32]. Elde edilen MEP yüzeyinden, negatif bölgenin esas olarak - $\mathrm{COOH}$ karboksil grubun oksijen 
$(\mathrm{C}=\mathrm{O})$ atomunda lokalize olduğu açıkça görülebilir ki molekülün en reaktif kısmıdır. Karboksil grubunun $(\mathrm{O}-\mathrm{H})$ $\mathrm{H}$ atomunda lokalize bir maksimum pozitif bölge bulunur ve bu da olası bir nükleofilik atak bölgesini gösterir.Buna göre, $\mathrm{H}$ atomunun en güçlü çekimi ve $\mathrm{O}$ atomunun en güçlü itmeyi gösterdiğini söyleyebiliriz. Pozitif ve negatif bölgeler, bileşiğin moleküller arası etkileşimlere sahip olabileceği bölge hakkında bilgi verir. $\mathrm{Bu}$ sonuçlardan, bileşik bir protein yapısı ile kenetlendiğinde (docking), reaksiyon yolunun moleküldeki $\mathrm{COOH}$ grubu yoluyla olacağı anlaşılmaktadır.

\section{E. Mulliken Atomik Yükler}

Atomik yükler moleküler sistemlerin dipol momentini, polarizasyonunu, elektronik yapısını, titreşim spektrumlarını ve daha birçok özelliği etkilediğinden, bu sistem için kuantum kimyasal hesaplamalarının uygulanmasında önemli bir rol oynar[33].Mulliken yük analizi hidrojen bağlanma olasılıklarını açıklar. PAO' nın atomik yükleri, mulliken populasyon analizi ile gaz fazında DFT/B3LYP/6-311++G(d,p) seviyesinde her atomun elektron popülasyonu belirlenerek hesaplanmış ve sonuçlar Tablo 4' te sunulmuştur. POA' nınmulliken yüklerinin histogramı ise Şekil 6' da gösterilmiştir.

Tablo 4. POA' nın B3LYP/6-311++G(d,p) seviyesinde hesaplanmış Mulliken atomik yükleri

\begin{tabular}{cccccc}
\hline $\begin{array}{c}\text { Atom } \\
\text { numarası }\end{array}$ & $\begin{array}{c}\text { Mulliken atomik } \\
\text { yükler }\end{array}$ & $\begin{array}{c}\text { Atom } \\
\text { numarası }\end{array}$ & $\begin{array}{c}\text { Mulliken atomik } \\
\text { yükler }\end{array}$ & $\begin{array}{c}\text { Atom } \\
\text { numarası }\end{array}$ & $\begin{array}{c}\text { Mulliken atomik } \\
\text { yükler }\end{array}$ \\
\hline C1 & 0,116 & $\mathrm{H} 19$ & 0,111 & $\mathrm{H} 38$ & 0,077 \\
C2 & $-0,553$ & $\mathrm{H} 20$ & 0,124 & $\mathrm{H} 39$ & 0,170 \\
C3 & $-0,345$ & $\mathrm{H} 21$ & 0,127 & $\mathrm{H} 40$ & 0,127 \\
C4 & $-0,184$ & $\mathrm{H} 22$ & 0,130 & $\mathrm{H} 41$ & 0,129 \\
C5 & $-0,026$ & $\mathrm{H} 23$ & 0,125 & $\mathrm{H} 42$ & 0,190 \\
C6 & $-0,150$ & $\mathrm{H} 24$ & 0,126 & $\mathrm{H} 43$ & 0,190 \\
C7 & $-0,579$ & $\mathrm{H} 25$ & 0,126 & $\mathrm{H} 44$ & 0,172 \\
C8 & $-0,157$ & $\mathrm{H} 26$ & 0,127 & $\mathrm{H} 45$ & 0,136 \\
C9 & $-0,076$ & $\mathrm{H} 27$ & 0,156 & $\mathrm{H} 46$ & 0,140 \\
C10 & $-0,056$ & $\mathrm{H} 28$ & 0,132 & $\mathrm{H} 47$ & 0,135 \\
C11 & $-0,189$ & $\mathrm{H} 29$ & 0,163 & & \\
C12 & $-0,379$ & $\mathrm{H} 30$ & 0,163 & & \\
C13 & $-0,115$ & $\mathrm{H} 31$ & 0,120 & & \\
C14 & $-0,261$ & $\mathrm{H} 32$ & 0,112 & & \\
C15 & $-0,196$ & $\mathrm{H} 33$ & 0,132 & & \\
C16 & $-0,653$ & $\mathrm{H} 34$ & 0,112 & & \\
O18 & $-0,272$ & $\mathrm{H} 35$ & 0,122 & \\
O17 & $-0,166$ & $\mathrm{H} 36$ & 0,120 & \\
H48 & 0,291 & $\mathrm{H} 37$ & 0,137 & \\
\hline
\end{tabular}

Mulliken analizi ile elde edilen sonuçlara göre hidrokarbon zinciri boyunca tüm hidrojen atomları, 0,111-0,190e aralığında değişen pozitif yüklere sahip iken, karboksil gruba ait hidrojen atomu 0,291 ile maksimum pozitif yüke sahiptir. Zincir boyunca tüm karbon atomları negatif yüklere sahip iken, karboksil gruba ait karbon atomu $\mathrm{C} 1$ pozitif yüke sahiptir.Mulliken popülasyon analizi, $\mathrm{O} 17$ ve $\mathrm{O} 18$ gibi iki elektronegatif atomun varlığını gösterir ve bu atomlar karboksil gruba ait C1 $(0,116 \mathrm{e})$ ve $\mathrm{H} 48(0,291 \mathrm{e})$ atomları üzerinde pozitif yük oluşturur. Karboksil gruptaki hidrojen ve karbon atomu iki oksijen atomunun daha elektronegatif olmasından dolayı, elektronlarını oksijen atomlarına kaybederler ve bu yüzden pozitiftir. Sonuç olarak, moleküler arası etkileşimde H48 atomu reseptörün negatif yüklü kısmı ile etkileşime girebilen, O18 atomu ise verici atomla etkileşime girebilen elektronegatif atomdur. 


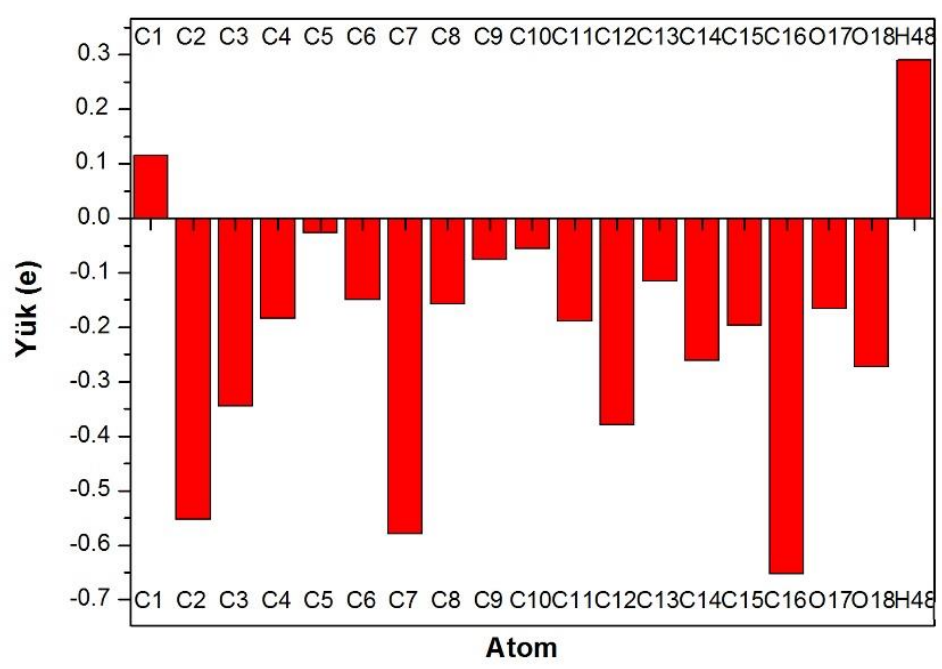

Şekil 6. POA' nın B3LYP/6-311++G(d,p) seviyesinde hesaplanmış Mulliken yük analizi histogramı

\section{F. Termodinamik Özellikler}

POA' nın enerjik, yapısal ve reaktivite özellikleri arasında tutarlı ilişkiler elde etmek için termodinamik özellikleri de belirlenmiştir. POA' nın sıfır noktası titreşim enerjisi (ZPE), termal enerjisi, spesifik 1sı kapasitesi, dönme sabitleri, entropi ve dipol momenti gibi termodinamik parametreleri 298,15 K ve 1 atm basınçta gaz fazında B3LYP/6-311++G(d,p) yöntemi ile hesaplanmıştır.Titreşim analizi ve istatistiksel termodinamik temeline dayanılarak, POA' nın standart istatistiksel termodinamik fonksiyonları harmonik frekans hesaplarından elde edilmiş veTablo 5' te listelenmiştir.

Dipol moment $(\mu)$, moleküllerin elektriksel ve optik özelliklerini anlamak için önemli bir parametredir. Üç boyutlu bir vektör olan dipol moment moleküler yük dağılımı hakkında bilgi verir. Bu nedenle, molekül üzerindeki yük hareketini göstermek için tanımlayıcı olarak kullanılabilir. Bir moleküldeki dipol moment vektörü, pozitif ve negatif yüklerin merkezlerine bağlıdır. Dipol momentin değeri nötr moleküller için kesin olarak belirlenirken, yüklü sistemler için orijin seçimine ve moleküler yönelime bağlıdır. Ayrıca dipol moment ne kadar büyük olursa moleküller arası etkileşimler o kadar güçlü olur[34].

Tablo 5. POA' nın B3LYP/6-311++G(d,p) seviyesinde hesaplanmış sıfır nokta titreşim enerjisi, dönme sabitleri, rotasyonel sıcaklığı, termal enerji, sabit hacimde molar kapasite, entropi ve dipol momenti

\begin{tabular}{cc}
\hline Parametreler & Değeri \\
\hline ZPE $\left(\mathrm{kcal} \mathrm{mol}^{-1}\right)$ & 273,02293 \\
Dönme sabitleri $(\mathrm{GHz})$ & 0,49546 \\
& 0,07120 \\
& 0,06389 \\
Dönme sıcaklı̆̆ $(\mathrm{K})$ & 0,02378 \\
& 0,00342 \\
Termal Enerji $\left(\mathrm{kcal} \mathrm{mol}{ }^{-1}\right)$ & 0,00307 \\
Toplam & \\
Öteleme & 287,364 \\
Dönme & 0,889 \\
Titreşim & 0,889 \\
& 285,586 \\
\hline
\end{tabular}




\begin{tabular}{|c|c|c|}
\hline & $\begin{array}{l}\text { BŞEÜ Fen Bilimleri Dergisi } \\
7(2), 553-573,2020\end{array}$ & $\begin{array}{r}\text { BSEU Journal of Science } \\
\text { DOI: } 10.35193 / \text { bseufbd. } 741065\end{array}$ \\
\hline $\begin{array}{l}\text { BIIECEKSEYHEDEBALI } \\
\text { UNIVERSITESI }\end{array}$ & & 58-7575 (http://dergipark.gov.tr/bseufbd) \\
\hline
\end{tabular}

Tablo 5. (devam ediyor.)

\begin{tabular}{cc}
\hline Parametreler & Değeri \\
\hline Sabit hacimde & \\
Toplar kapasite $\left(\mathrm{cal} \mathrm{mol}^{-1} \mathrm{~K}^{-1}\right)$ & 80,841 \\
Öteleme & 2,981 \\
Dönme & 2,981 \\
Titreşim & 74,879 \\
Entropi (cal mol $\left.{ }^{-1} \mathrm{~K}^{-1}\right)$ & \\
Toplam & 173,078 \\
Öteleme & 42,499 \\
Dönme & 36,210 \\
Titreşim & 94,369 \\
Dipol moment (Debye) & \\
$\mu_{\mathrm{x}}$ & $-0,2917$ \\
$\mu_{\mathrm{y}}$ & $-0,1145$ \\
$\mu_{\mathrm{z}}$ & $-1,6759$ \\
$\mu_{\text {toplam }}$ & 1,7049 \\
\hline
\end{tabular}

Ayrıca bileşiğin termodinamik özellikleri (1sı kapasitesi, entropi ve entalpi) farklı sıcaklıklarda da hesaplanmıştır. Burada tüm termodinamik hesaplar gaz fazında yapılmıştır.

Tablo 6. POA' nın 100 ile $1000 \mathrm{~K}$ aralığında B3LYP/6-311++G(d,p) metodu ile hesaplanan termodinamik parametreleri

\begin{tabular}{cccc}
\hline $\mathrm{T}(\mathrm{K})$ & $\mathrm{C}_{\mathrm{p}, \mathrm{m}}^{\mathrm{o}}\left(\mathrm{Cal} \mathrm{mol}^{-1} \mathrm{~K}^{-1}\right)$ & $\mathrm{S}_{\mathrm{m}}^{\mathrm{o}}\left(\mathrm{Cal} \mathrm{mol}^{-1} \mathrm{~K}^{-1}\right)$ & $\mathrm{H}_{\mathrm{m}}^{\mathrm{o}}\left(\mathrm{kCal} \mathrm{mol}{ }^{-1}\right)$ \\
\hline 100 & 48,544 & 109,852 & 275,592 \\
200 & 67,170 & 144,844 & 280,547 \\
298,15 & 89,155 & 173,078 & 287,364 \\
300 & 89,607 & 173,592 & 287,514 \\
400 & 114,368 & 200,948 & 296,884 \\
500 & 137,172 & 227,564 & 308,655 \\
600 & 156,660 & 253,193 & 322,543 \\
700 & 173,080 & 277,636 & 338,222 \\
800 & 186,990 & 300,836 & 355,413 \\
900 & 198,865 & 322,891 & 373,889 \\
1000 & 209,059 & 343,646 & 393,467 \\
\hline
\end{tabular}

Tablo 6' dan görüldüğü gibi, termodinamik fonksiyonlar 100 ila $1000 \mathrm{~K}$ arasında artan sıcaklıkla artmıştır, çünkü sıcaklığı arttırmak moleküler titreşimin yoğunluğunda bir artışa neden olmaktadır [35]. Bu termodinamik fonksiyonlar ile sıcaklık arasındaki korelasyon grafiği Şekil 7' de gösterilmektedir ve korelasyon denklemleri aşağıda verilmektedir:

$$
\begin{array}{lll}
\mathrm{C}_{\mathrm{p}, \mathrm{m}}^{\mathrm{o}}(\mathrm{T})=16,13861+0,28304 \mathrm{~T}-8,83428 \times 10^{-5} \mathrm{~T}^{2} & , & \mathrm{R}^{2}=0,99709 \\
\mathrm{~S}_{\mathrm{m}}^{\mathrm{o}}(\mathrm{T})=79,52607+0,33084 \mathrm{~T}-6,72727 \times 10^{-5} \mathrm{~T}^{2} & , & \mathrm{R}^{2}=0,99977 \\
\mathrm{H}_{\mathrm{m}}^{\mathrm{o}}(\mathrm{T})=270,96293+0,02853 \mathrm{~T}+9,49664 \times 10^{-5} \mathrm{~T}^{2}, & \mathrm{R}^{2}=0,99967
\end{array}
$$




\begin{tabular}{|c|c|c|}
\hline & $\begin{array}{l}\text { BŞEÜ Fen Bilimleri Dergisi } \\
7(2), 553-573,2020\end{array}$ & $\begin{array}{r}\text { BSEU Journal of Science } \\
\text { DOI: } 10.35193 / \text { bseufbd. } 741065\end{array}$ \\
\hline & & 58-7575 (http://dergipark.gov.tr/bseufbd) \\
\hline
\end{tabular}

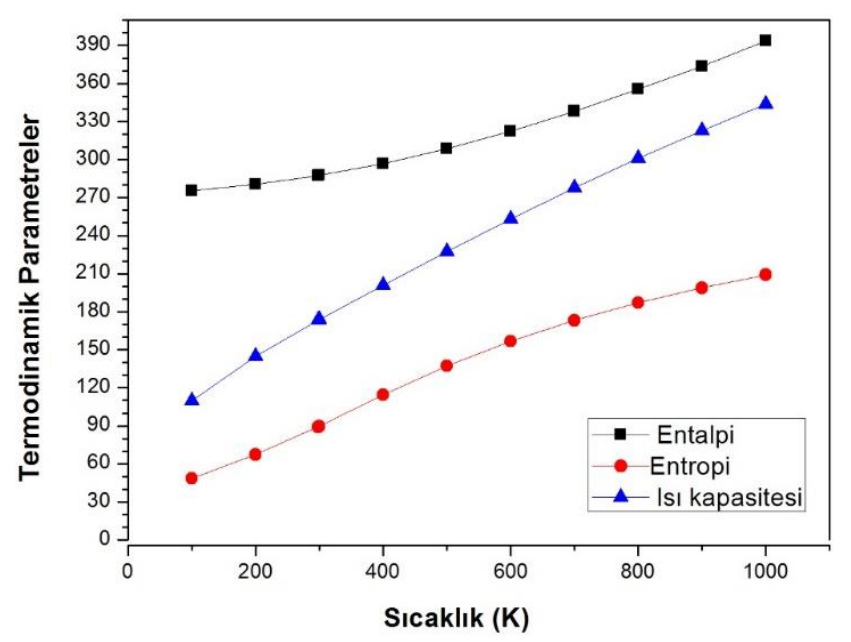

Şekil 7. POA molekülünün farklı sıcaklıklardaki termodinamik özelliklerinin korelasyon grafikleri

Is1 kapasitesi, entropi ve entalpi gibi termodinamik özellikler ile sıcaklıklar arasındaki korelasyon denklemleri, kuadratik formüller ile fit edilmiş ve ilgili regresyon faktörleri $\left(R^{2}\right)$ sırasıyla $0,99709,0,99977$ ve 0,99967 elde edilmiştir.

Yukarıda adı geçen termodinamik parametreler, POA hakkında gelecekte yapılacak çalışmalar için yararlı bilgiler sağlayabilir. Örneğin, POA ile başka bir bileşik arasındaki etkileşimi araştırdığımızda, bu denklemlerden termodinamik özellikler elde edilebilir ve daha sonra reaksiyonun kendiliğindenliğini değerlendirmemizde yardımcı olacak reaksiyonun Gibbs serbest enerjisindeki değişimi hesaplamak için kullanılabilir. Ayrıca bu denklemler diğer termodinamik fonksiyonları hesaplamak ve termodinamiğin ikinci yasasına göre kimyasal reaksiyonların yönünü tahmin etmek için de kullanılabilirler.

\section{SONUÇLAR}

$\mathrm{Bu}$ çalışmada pek çok biyolojik süreçte önemli rol oynayan cis-POA' nın yapısal, titreşimsel ve elektronik özellikleri kuantum kimyasalyöntemler kullanılarak ilk kez karakterize edilmiş ve tartışılmıştır. Molekülün geometrik parametreleri, harmonik titreşim frekansları, moleküler orbital (HOMO-LUMO) enerjileri ve bu enerji değerleri ile ilişkili diğer özellikleri DFT/B3LYP/6-311++G(d,p)seviyesinde hesaplanmıştır. Geometrik parametrelerin deneysel ve teorik sonuçları arasında çizilen korelasyon grafiklerinden elde eldilen korelasyon katsayıları bu sonuçların uyum içinde olduğunu göstermektedir. PAO' nın hesaplanan ve literatürden elde edilen deneysel FT-IR spektrumundaki temel titreşim modları karşılaştırılmış ve tartışılmıştır. POA' nın hesaplanan infrared spektrumunda O-H gerilme titreşim moduna ait band gözlenirken, sıvı haldeki POA'nın deneysel ATR-FTIR spektrumunda bu spektral bölgede bandın gözlenmemesi ve spektrumdaki en güçlü mod olan $v(\mathrm{C}=\mathrm{O})$ gerilme modunun deneysel spektrumda teorik spektrumda hesaplanan değere göre daha düşük dalgasayısında gözlenmesimolekülün sıvı formda dimer yapıda olduğunu göstermektedir. POA' nın hesaplanan mulliken atomik yükleri, karboksil grubun oksijen atomunun elektron alıcısı, hidrojen atomununvericisi olduğunun göstergesidir. Bu sonuçlardan, moleküler arası etkileşimde reaksiyon yolunun moleküldeki $\mathrm{COOH}$ grubu yoluyla olacağıaçıkça görülmektedir. POA' nınbirçok aktif moleküle göre yüksek HOMO-LUMO enerji aralığına, yüksek sertlik ve düşük yumuşaklık parametresine sahip olması düşük kimyasal aktivite ve yüksek kinetik stabilite ile kararlı bir yapıya sahip olduğunu göstermektedir. MEP haritasındaki sonuçlar, negatif potansiyel bölgesinin karboksil grubun oksijen atomları etrafında olduğunu, nükleofilik reaksiyonlar tanımlayan maksimum pozitif bölgenin ise karboksil grubun hidrojen atomu etrafinda olduğunu göstermiş ve bileşiğin kovalent olmayan etkileşimlere sahip olabileceği bölgeler hakkında bilgi sahibi olmamızı săglamışı̆ır. Isı kapasitesi, entropi, entalpi ve sıcaklık arasında, diğer termodinamik fonksiyonları hesaplamak ve oluşabilecek kimyasal reaksiyonların yönünü tahmin etmek için de kullanılabilecek korelasyon denklemleri elde edilmiş ve tüm termodinamik parametrelerin, artan sicaklıkla birlikte arttığı bulunmuştur. Yaptığımız bu teorik 
çalışmamolekülün geometrikve elektronik yapısına bağlı değişen biyolojik aktivitesini anlamak için önem taşımaktadır.

\section{KAYNAKLAR}

[1] Gennis, R.B. (1989). Biomembranes: Molecular Structure and Function Springer-Verlag, New York,.533.

[2] Small, D.M. (1986). The physical chemistry of lipids : from alkanes to phospholipids ${ }^{\text {th }}$ ed. Springer, London, 692.

[3] Jakobsen, M.U., Overvad, K., Dyerberg, J., Schroll, M., \& Heitmann, B.L. (2004). Dietary fat and risk of coronary heart disease: Possible effect modification by gender and age. American Journal of Epidemiology, $160,141-149$.

[4] Yamamoto, Y., Kawamura, Y., Yamazaki, Y., Kijima, T., Morikawa, T., \& Nonomura, Y. (2015). Palmitoleic Acid Calcium Salt: A Lubricant and Bactericidal Powder from Natural Lipids. Journal of Oleo Science, 64, 283-288.

[5] Yoon, W.-J., Kim, M.-J., Moon, J.-Y., Kang, H.-J., Kim, G.-O., \& Lee, N.H. (2010). Effect of Palmitoleic Acid on Melanogenic Protein Expression in Murine B16 Melanoma. Journal of Oleo Science, 59, 315-319.

[6] Fischer, C.L., Drake, D.R., Dawson, D. V., Blanchette, D.R., Brogden, K.A., \& Wertz, P.W. (2012). Antibacterial Activity of Sphingoid Bases and Fatty Acids against Gram-Positive and Gram-Negative Bacteria. Antimicrobial Agents and Chemotherapy, 56, 1157-1161.

[7] Wille, J.J. \& Kydonieus, A. (2003). Palmitoleic Acid Isomer (C16:1 $\Delta 6)$ in Human Skin Sebum Is Effective against Gram-Positive Bacteria. Skin Pharmacology and Physiology, 16, 176-187.

[8] Çimen, I., Kocatürk, B., Koyuncu, S., Tufanlı, Ö., Onat, U.I., Yıldırım, A.D., et al. (2016). Prevention of atherosclerosis by bioactive palmitoleate through suppression of organelle stress and inflammasome activation. Science Translational Medicine, 8, 358ra126.

[9] Cimen, I., Yildirim, Z., Dogan, A.E., Yildirim, A.D., Tufanli, O., Onat, U.I., et al. (2019). Double bond configuration of palmitoleate is critical for atheroprotection. Molecular Metabolism, 28, 58-72.

[10] Kaneko, F., Yano, J., \&Sato, K. (1998). Diversity in the fatty-acid conformation and chain packing of cisunsaturated lipids. Current Opinion in Structural Biology, 8, 417-425.

[11] Kaneko, F., Yamazaki, K., Kobayashi, M., Sato, K., \& Suzuki, M. (1994). Vibrational spectroscopic study on polymorphism of erucic acid and palmitoleic acid: $\gamma 1 \rightarrow \alpha 1$ and $\gamma \rightarrow \alpha$ reversible solid state phase transitions. Spectrochimica Acta Part A: Molecular Spectroscopy, 50, 1589-1603.

[12] Frisch, M.J., Trucks, G.W., Schlegel, H.B., Scuseria, G.E., Robb, M.A., Cheeseman, J.R., Scalmani, G., Barone, V., Mennucci, B., Petersson, G.A., Nakatsuji, H., Caricato, M., Li, X., Hratchian, H.P., Izmaylov, A.F., Bloino, J., Zheng, G., Sonnenberg, J.L., Hada, M., Ehara, M., Toyota, K., Fukuda, R., Hasegawa, J.,Ishida, M., Nakajima, T., Honda, Y., Kitao, O., Nakai, H., Vreven, T., Montgomery, J.A., Peralta Jr, J.E., Ogliaro, F., Bearpark, M., Heyd, J.J., Brothers, E., Kudin, K.N., Staroverov, V.N., Kobayashi, R., Normand, J., Raghavachari, K., Rendell, A., Burant, J.C., Iyengar, S.S., Tomasi, J., Cossi, M., Rega, N., Millam, J.M., Klene, M., Knox, J.E., Cross, J.B., Bakken, V., Adamo, C., Jaramillo, J., Gomperts, R., Stratmann, R.E., Yazyev, O., Austin, A.J., Cammi, R., Pomelli, C., Ochterski, J.W., Martin, R.L., Morokuma, K., Zakrzewski, V.G., Voth, G.A., Salvador, P., Dannenberg, J.J., Dapprich, S., Daniels, A.D., Farkas, O., Foresman, J.B., Ortiz, J.V., Cioslowski, J., Fox, D.J., Gaussian 09, Revision A.0.2, Gaussian, Inc., Wallingford CT, 2009.

[13] Sundaraganesan, N., Ilakiamani, S., Saleem, H., Wojciechowski, P.M., \& Michalska, D. (2005). FT-Raman and FT-IR spectra, vibrational assignments and density functional studies of 5-bromo-2-nitropyridine. Spectrochimica Acta - Part A: Molecular and Biomolecular Spectroscopy, 61, 2995-3001. 
[14] Jamróz M H (2010) Vibrational Energy Distribution Analysis VEDA 4, Warsaw.

[15] Dennington, R.,Keith, T.A., \& Millam, J.M. (2008). Gaussview 5.0.8, Gaussian Inc., Wallingford, CT.

[16] Abrahamsson, S. \& Ryderstedt-Nahringbauer, I. (1962). The crystal structure of the low-melting form of oleic acid. Acta Crystallographica, 15, 1261-1268.

[17] Kaneko, F., Yamazaki, K., Kobayashi, M., Kitagawa, Y., Matsuura, Y., Sato, K., et al. (1993). Structure of the $\gamma$ phase of erucic acid. Acta Crystallographica Section C Crystal Structure Communications, 49, 1232 1234 .

[18] Copyright @ 2012-2018 Bio-Rad Laboratories, Inc. All Rights Reserved. https://spectrabase.com/spectrum/8R37FJJII3H

[19] Machado, N.F.L., De Carvalho, L.A.E.B., Otero, J.C., \& Marques, M.P.M. (2012). The autooxidation process in linoleic acid screened by Raman spectroscopy. Journal of Raman Spectroscopy, 43, 1991-2000.

[20] Gocen, T., Haman Bayarı, S., \& Guven, M. H. (2017). Linoleic acid and its potassium and sodium salts: A combined experimental and theoretical study. Journal of Molecular Structure, 1150, 68-81.

[21] Lewandowski, W., Kalinowska, M., \& Lewandowska, H. (2005). The influence of halogens on the electronic system of biologically important ligands: Spectroscopic study of halogenobenzoic acids, halogenobenzoates and 5-halogenouracils. Inorganica Chimica Acta, 358, 2155-2166.

[22] Silverstein, R.M., Bassler, G.C. \& Morrill, T.C. (1976). Spectrometric identification of organic compounds, 3rd edition. Journal of Molecular Structure, 30, 424-425.

[23] Lewis, D.F. V., Ioannides, C., \& Parke, D. V. (1994). Interaction of a series of nitriles with the alcoholinducible isoform of P450: Computer analysis of structure-activity relationships. Xenobiotica, 24, 401408.

[24] Pearson, R.G. (1988). Electronic spectra and chemical reactivity. Journal of the American Chemical Society, 110, 2092-2097.

[25] Zhan, C.-G., Nichols, J.A., \& Dixon, D.A. (2003). Ionization Potential, Electron Affinity, Electronegativity, Hardness, and Electron Excitation Energy: Molecular Properties from Density Functional Theory Orbital Energies. The Journal of Physical Chemistry A, 107, 4184-4195.

[26] Sheela, N.R., Muthu, S., \& Sampathkrishnan, S. (2014). Molecular orbital studies (hardness, chemical potential and electrophilicity), vibrational investigation and theoretical NBO analysis of 4-4'-(1H-1,2,4triazol-1-yl methylene) dibenzonitrile based on abinitio and DFT methods. Spectrochimica Acta Part A: Molecular and Biomolecular Spectroscopy, 120, 237-251.

[27] Koopmans, T. (1934). Über die Zuordnung von Wellenfunktionen und Eigenwerten zu den Einzelnen Elektronen Eines Atoms. Physica, 1, 104-113.

[28] Parr, R.G., Szentpály, L. V., \& Liu, S. (1999). Electrophilicity Index. Journal of the American Chemical Society, 121, 1922-1924.

[29] Eşme, A. \& Sağdınç, S.G. (2017). Spectroscopic (FT-IR, FT-Raman, UV-Vis) analysis, conformational, HOMO-LUMO, NBO and NLO calculations on monomeric and dimeric structures of 4pyridazinecarboxylic acid by HF and DFT methods. Journal of Molecular Structure, 1147, 322-334.

[30] Chidangil, S. \& Mishra, P.C. (1997). Structure-Activity Relationship for Some 2',3'-Dideoxynucleoside Anti-HIV Drugs Using Molecular Electrostatic Potential Mapping. Journal of Molecular Modeling, 3, 172181.

[31] Mishra, P.C. , Kumar, A., Murray, J.S., \& Sen, K.D. (1996). Theoretical and Computational Chemistry 
Book Series. in: Mol. Electrost. Potentials Concepts Appl. Elsevier, Amsterdam, 257.

[32] Gupta, V.P., Sharma, A., Virdi, A., \& Ram, V. (2006). Structural and spectroscopic studies on some chloropyrimidine derivatives by experimental and quantum chemical methods. Spectrochimica Acta Part A: Molecular and Biomolecular Spectroscopy, 64, 57-67.

[33] Mulliken, R.S. (1955). Electronic Population Analysis on LCAO-MO Molecular Wave Functions. I. The Journal of Chemical Physics, 23, 1833-1840.

[34] Karthikeyan, N., Joseph Prince, J., Ramalingam, S.,\& Periandy, S. (2014). Vibrational spectroscopic [FTIR, FT-Raman] investigation on (2,4,5-Trichlorophenoxy) Acetic acid using computational [HF and DFT] analysis. Spectrochimica Acta Part A: Molecular and Biomolecular Spectroscopy, 124, 165-177.

[35] Bopp, F., Meixner, J., \& Kestin, J. (1967). Thermodynamics and Statistical Mechanics Academic Press Inc., New York, 420. 